\title{
Induction of Broad-Spectrum Protective Immunity against Disparate Cryptococcus Serotypes
}

\author{
Marley C. Caballero Van Dyke ${ }^{1,2}$, Ashok K. Chaturvedi, , Sarah E. Hardison ${ }^{1,2}$, \\ Chrissy M. Leopold Wager ${ }^{1,2}$, Natalia Castro-Lopez ${ }^{1,2}$, Camaron R. Hole ${ }^{1,2}$, \\ Karen L. Wozniak ${ }^{1,2}$ and Floyd L. Wormley Jr. ${ }^{1,2 *}$
}

${ }^{1}$ Department of Biology, The University of Texas at San Antonio, San Antonio, TX, United States, ${ }^{2}$ The South Texas Center for Emerging Infectious Diseases, The University of Texas at San Antonio, San Antonio, TX, United States

Cryptococcosis is a fungal disease caused by multiple Cryptococcus serotypes; particularly C. neoformans (serotypes A and D) and C. gattii (serotypes B and C). To date, there is no clinically available vaccine to prevent cryptococcosis. Mice given an experimental

OPEN ACCESS

Edited by: Amariliz Rivera, New Jersey Medical School, United States

Reviewed by:

Liliane Mukaremera,

University of Minnesota

Twin Cities, United States

Chaoyang Xue,

Rutgers University-Newark, United States

${ }^{*}$ Correspondence: Floyd L. Wormley Jr. floyd.wormley@utsa.edu

Specialty section: This article was submitted to Microbial Immunology, a section of the journal Frontiers in Immunology

Received: 25 May 2017 Accepted: 04 October 2017 Published: 30 October 2017

Citation:

Van Dyke MCC, Chaturvedi AK, Hardison SE, Leopold Wager CM,

Castro-Lopez N, Hole CR,

Wozniak KL and Wormley FL Jr.

(2017) Induction of Broad-Spectrum

Protective Immunity against Disparate

Cryptococcus Serotypes.

Front. Immunol. 8:1359.

doi: 10.3389/fimmu.2017.01359 pulmonary vaccination with a $C$. neoformans serotype $A$ strain engineered to produce interferon- $\gamma$, denoted H99 $\gamma$, are protected against a subsequent otherwise lethal experimental infection with $C$. neoformans serotype A. Thus, we determined the efficacy of immunization with $\mathrm{C}$. neoformans strain $\mathrm{H} 99 \gamma$ to elicit broad-spectrum protection in BALB/c mice against multiple disparate Cryptococcus serotypes. We observed significantly increased survival rates and significantly decreased pulmonary fungal burden in H99y immunized mice challenged with Cryptococcus serotypes A, B, or D compared

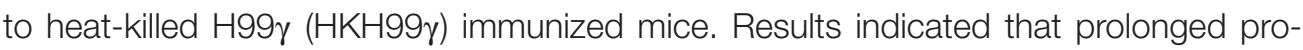
tection against Cryptococcus serotypes B or D in H99y immunized mice was CD4+ T cell dependent and associated with the induction of predominantly Th1-type cytokine responses. Interestingly, immunization with $\mathrm{H} 99 \gamma$ did not elicit greater protection against challenge with the Cryptococcus serotype $\mathrm{C}$ tested either due to low overall virulence of this strain or enhanced capacity of this strain to evade host immunity. Altogether, these studies provide "proof-of-concept" for the development of a cryptococcal vaccine that provides cross-protection against multiple disparate serotypes of Cryptococcus.

Keywords: Cryptococcus neoformans, Cryptococcus gattii, cryptococcosis, host-fungal interaction, fungal vaccines, fungal immunology

\section{INTRODUCTION}

Cryptococcosis is a worldwide fungal disease caused by species in the Cryptococcus neoformans/ Cryptococcus gattii species complex (1). C. neoformans and C. gattii cause pneumonia in immunocompromized and immunocompetent individuals and can disseminate to the central nervous system resulting in life-threatening meningoencephalitis. Cryptococcal meningoencephalitis is the most common disseminated fungal disease in AIDS patients (2) and is responsible for $15 \%$ of AIDS-related deaths (3). The former species C. neoformans is divided into two species, C. neoformans and C. deneoformans. C. neoformans (serotype A) is distributed worldwide with the highest amount of disease cases occurring in sub-Saharan Africa where approximately 21.7 million people 
currently live with AIDS, and C. deneoformans (serotype D) is predominantly geographically restricted to Europe and Latin America (3-5). Conversely, C. gattii (serotype B C. deuterogattii and serotype C C. bacillisporus) predominantly occurs in tropical and subtropical climates (6-8). However, cryptococcosis due to C. gattii is also observed in more temperate climates including British Columbia, Canada, and southwest, southeast, northwest, and northeast regions of the USA and in Mediterranean Europe (9-16). Species in the C. neoformans/C. gattii complex can cause disease in both apparently healthy individuals and immunocompromized hosts such as AIDS patients, individuals on prolonged treatment with corticosteroids, and in patients on immunosuppressive drugs to prevent rejection of solid organ transplants [reviewed by Kwon-Chung et al. (17)] (7, 8, 18-20). There is a higher occurrence of $C$. gattii disease in immunocompetent individuals compared to C. neoformans (20-22). Currently, there is no vaccine clinically available to prevent cryptococcosis and current drug therapies are often rendered ineffective due to the development of drug resistance by Cryptococcus or drug toxicity (23). Thus, the overall incidence of disease and mortality associated with cryptococcosis and the potential expanded geographic distribution of the pathogen indicates an urgent need for immunotherapies and/or vaccines to combat cryptococcosis.

Results from multiple studies in both humans and animal models suggest that cell-mediated immunity (CMI) by Th1-type $\mathrm{CD}^{+} \mathrm{T}$ cells is the primary host defense against cryptococcosis $(24,25)$. However, studies suggest that the host immune response against C. gattii and C. neoformans differ in that C. gattii infection appears to be more immune suppressive, which may explain the disparate clinical presentation displayed by these different species (26-31). Differences in the host response to various Cryptococcus serotypes complicate efforts to devise a vaccine that can provide broad-spectrum protection against cryptococcosis caused by disparate Cryptococcus serotypes.

Historically, several approaches have been employed to develop an anti-Cryptococcus vaccine that generates protective antibody mediated and/or cell-mediated immune responses against Cryptococcus [reviewed in Ref. (32).]. Recently, studies have demonstrated that mice given an immunization with glucan particles (GPs) packaged with alkaline extracts from mutant C. neoformans or C. gattii strains develop increased survival against cryptococcosis (33). Other, studies showed cross-protection of mice immunized with a heat-killed chitosan deficient C. neoformans strain against challenge with $C$. neoformans or C. gattii (34). Rella and colleagues showed that mice vaccinated with a $C$. neoformans mutant strain that lacks the enzyme sterylglucosidase $(\Delta s g l 1)$ are protected against challenge with both C. neoformans H99 and C. gattii R265 strains (35).

Studies have shown that mice immunized with a C. neoformans strain H99, serotype A, engineered to produce murine interferon (IFN)- $\gamma$, denoted $\mathrm{H} 99 \gamma$, develop protective Th1-type immune responses against a subsequent otherwise lethal pulmonary challenge with wild-type C. neoformans strain $\operatorname{H99}(25,36-40)$. The presence of $\mathrm{CD}^{+}$and/or $\mathrm{CD}^{+} \mathrm{T}$ cells are required for protection during the immunization phase with $\mathrm{H} 99 \gamma$ but not during subsequent challenge with C. neoformans strain H99 (40). These results and those by Rella et al. highlight that protection against pulmonary cryptococcosis in immunocompetent hosts can be maintained in immunosuppressed hosts and that the development of a prophylactic vaccine against cryptococcosis is feasible. Nonetheless, no studies have shown that protection elicited following immunization with one Cryptococcus serotype provides similar levels of cross-protection against all four Cryptococcus serotypes.

Consequently, the objective of these studies was to determine the potential for an anti-cryptococcal vaccine to provide broadspectrum protection against multiple disparate Cryptococcus serotypes. We therefore determined the efficacy of immunization with C. neoformans strain $\mathrm{H} 99 \gamma$ to elicit protection against experimental pulmonary challenge with disparate cryptococcal serotypes in mice. We demonstrate that immunization with $C$. neoformans strain $\mathrm{H} 99 \gamma$, serotype A, elicits a predominantly protective Th1-type immune response against challenge with different serotypes of Cryptococcus. These data support the premise that development of a broad-spectrum prophylactic vaccine against cryptococcosis is achievable.

\section{MATERIALS AND METHODS}

\section{Mice}

Female BALB/c (National Cancer Institute/Charles River Laboratories) 4-6 weeks of age were used throughout these studies. Mice were housed at the University of Texas at San Antonio Small Animal Laboratory Vivarium and all animal experiments were conducted following NIH guidelines for housing and care of laboratory animals and in accordance with protocols approved by the Institutional Animal Care and Use Committee (protocol number MU021) of the University of Texas at San Antonio.

\section{Strains and Media}

Cryptococcus neoformans strains H99 (serotype A, mating type $\alpha$ ), C. deuterogattii strain R265 (serotype B; a kind gift from Dr. Joseph Heitman ofDukeUniversity MedicalCenterin Durham, NC, USA), C. bacillisporus strain WSA87 (serotype C), and C. deneoformans strain R4247 (serotype D) (each kind gifts from Dr. Brian Wickes of the UT Health San Antonio, San Antonio, TX, USA), and H99 $\gamma$ [an IFN-gamma producing C. neoformans strain derived from $\mathrm{H} 99$ (38)] were recovered from $15 \%$ glycerol stocks stored at $-80^{\circ} \mathrm{C}$ prior to use in the experiments described herein. The strains were maintained on yeast-extract-peptone-dextrose (YPD) media ( $1 \%$ yeast extract, $2 \%$ peptone, $2 \%$ dextrose, and $2 \%$ Bacto agar). Yeast cells were grown for $16 \mathrm{~h}$ at $30^{\circ} \mathrm{C}$ with shaking in YPD broth, collected by centrifugation, washed three times with sterile PBS, and viable yeasts were quantified using trypan blue dye exclusion on a hemacytometer.

\section{Pulmonary Cryptococcal Infections}

Cryptococcal infections were initiated as previously described $(25,41)$. Briefly, mice were anesthetized with $2 \%$ isoflurane using a rodent anesthesia device (Eagle Eye Anesthesia, Jacksonville, FL, USA) and given an intranasal inoculation with $1 \times 10^{4} \mathrm{CFU}$ of Cryptococcus strains H99, R265, WSA87, or R4247 in $50 \mu$ l of sterile PBS. Alternatively, mice were given an intranasal immunization 
with $1 \times 10^{4} \mathrm{CFU}$ of $\mathrm{C}$. neoformans strain H99 $\gamma$ or heat-killed H99 $\gamma$ (HKH99 $\gamma$ ) yeasts in $50 \mu \mathrm{l}$ of sterile PBS, allowed 70 days to resolve the infection and subsequently given an intranasal challenge with $1 \times 10^{4} \mathrm{CFU}$ of H99, R265, WSA87, or R4247 in $50 \mu \mathrm{l}$ of sterile PBS. The inocula used for immunizations and challenges were verified by quantitative culture on YPD agar. The mice were monitored by inspection twice daily. Mice were euthanized on pre-determined days post challenge and lung tissues excised using aseptic technique. Tissues were homogenized in $1 \mathrm{ml}$ of sterile PBS followed by culture of 10-fold dilutions of each tissue on YPD agar supplemented with chloramphenicol (Mediatech Inc., Herndon, VA, USA). CFU were enumerated following incubation at $30^{\circ} \mathrm{C}$ for $48 \mathrm{~h}$. Alternatively, mice intended for survival analysis were monitored by inspection twice daily and euthanized if they appeared to be in pain or moribund (weight loss, ataxia, listlessness, or failure to groom). Mice were euthanized using $\mathrm{CO}_{2}$ inhalation followed by cervical dislocation.

\section{T Cell Depletion}

Mice were immunized with $1 \times 10^{4} \mathrm{CFU}$ of $C$. neoformans strain H99 $\gamma$ as described above. After 70 days of rest, mice were depleted of $\mathrm{CD}^{+} \mathrm{T}$ cells, $\mathrm{CD} 8^{+} \mathrm{T}$ cells, or both $\mathrm{CD} 4^{+} / \mathrm{CD} 8^{+} \mathrm{T}$ cell subsets via intraperitoneal administration of anti-CD4 (clone GK1.5) and anti-CD8 (clone 2.43) antibodies (Table 1) (each from Cell Culture Company/NCCC, Minneapolis, MN, USA) or given isotype control antibody (rat $\operatorname{IgG}_{2 \mathrm{~b}}$ ) (BioXCell, Lebanon, NH, USA). Each mouse received $200 \mu \mathrm{g}$ of GK1.5 and/or 2.43 or control rat $\mathrm{IgG}_{2 \mathrm{~b}}$ antibodies in a volume of $200 \mu \mathrm{l} \mathrm{PBS} 48 \mathrm{~h}$ prior to challenge with H99, R265, WSA87, or R4247 and weekly thereafter during the observation period. The efficiency of $\mathrm{T}$ cell depletion in lungs and spleens was assessed by flow cytometric analysis using antiCD4 and anti-CD8 antibodies that bind epitopes of the CD4 and CD8 protein at locations distinct from GK1.5 and 2.43. Efficiency was determined to be $>98 \%$ at each anatomic location for each

TABLE 1 | Antibodies used in flow cytometry.

\begin{tabular}{lll}
\hline mAb & Clone & Manufacturer \\
\hline CD45R (B220)-PE & RA3-6B2 & BD Biosciences \\
CD11c-Pe-Cy7 & N418 & eBiosciences \\
CD11c-PE & N418 & eBiosciences \\
CD11b-Pe-Cy7 & M1170 & eBiosciences \\
CD45-APC & $30-F 11$ & eBiosciences \\
CD45-Pe-Cy7 & $30-F 11$ & eBiosciences \\
F4/80-APC & BM8 & Life Technologies \\
Ly6G-PE & 1 A8 & BD Biosciences \\
T cell mix-CD8a APC, CD3e, & CD8a 53-6.7, CD3e-145- & BD Biosciences \\
Pe-Cy7, CD4 PE & $2 C 11$, CD4 RM4-5 & \\
CD19-PE & $1 D 3$ & BD Biosciences \\
Siglec-F-PE & E50-2440 & BD Biosciences \\
CD3e-Pe-Cy7 & $145-2 C 11$ & eBiosciences \\
CD4-PE & RM4-5 & BD Biosciences \\
Intracellular flow & & \\
Interferon- $\gamma$-APC & XMG1.2 & eBiosciences \\
IL-4-APC & $11 B 11$ & eBiosciences \\
IL-17A-APC & eBio17B7 & eBiosciences \\
Depletion antibodies & & \\
Anti-CD4 & GK1.5 & Cell Culture Company \\
Anti-CD8 & 2.43 & Cell Culture Company
\end{tabular}

depletion via comparison of $\mathrm{T}$ cell subsets in treated mice with those in control animals.

\section{Cytokine Analysis}

As previously described $(25,41)$, cytokine levels in lung tissues were analyzed using the Bio-Plex protein array system (Luminexbased technology; Bio-Rad Laboratories, Hercules, CA, USA). Briefly, the left lobe of the lung was excised and homogenized in ice-cold sterile PBS $(1 \mathrm{ml})$. An aliquot $(50 \mu \mathrm{l})$ was taken to quantify the pulmonary fungal burden and an anti-protease buffer solution containing PBS, protease inhibitors (inhibiting cysteine, serine, and other metalloproteinases), and $0.05 \%$ Triton $\mathrm{X}-100$ was added to the homogenate and then clarified by centrifugation $(800 \times g)$ for $10 \mathrm{~min}$. Supernatants from pulmonary homogenates were assayed for the presence of IL- $1 \alpha$, IL-1 $\beta$, IL-1, IL-3, IL-4, IL-5, IL-6, IL-9, IL-10, IL-12(p40), IL-12(p70), IL-13, IL-17A, CCL5/RANTES, CCL11/Eotaxin, CXCL1/KC, CCL3/ MIP- $1 \alpha$, CCL4/MIP-1 $\beta$, CCL2/MCP-1, G-CSF, GM-CSF, TNF- $\alpha$, and IFN $-\gamma$.

\section{Pulmonary Leukocyte Isolation}

Lungs were excised on days 3, 7, and 14 post challenge and digested enzymatically at $37^{\circ} \mathrm{C}$ for $30 \mathrm{~min}$ in $10 \mathrm{ml}$ of digestion buffer (RPMI 1640 and $1 \mathrm{mg} / \mathrm{ml}$ of collagenase type IV) (Sigma Chemical Co., St. Louis, MO, USA) with intermittent (every $10 \mathrm{~min}$ ) stomacher homogenizations as previously described (25, 41). The digested tissues were then filtered through sterile nylon filters of various pore sizes (70 and $40 \mu \mathrm{m}$; BD Biosciences) and washed with sterile HBSS to enrich for leukocytes. Erythrocytes were lysed by incubation in $\mathrm{NH}_{4} \mathrm{Cl}$ buffer $\left(0.859 \% \mathrm{NH}_{4} \mathrm{Cl}, 0.1 \%\right.$ $\mathrm{KHCO}_{3}, 0.0372 \% \mathrm{Na}_{2} \mathrm{EDTA} \mathrm{pH} 7.4$ ) for 3 min on ice followed by the addition of a twofold excess of PBS. The leukocyte population was then washed twice with sterile PBS, suspended in sterile PBS $+2 \%$ heat-inactivated fetal bovine serum (FACS buffer), and enumerated in a hemacytometer using trypan blue dye exclusion. Flow cytometry analysis was used to determine the percentage of each leukocyte population as well as the absolute number of total leukocytes $\left(\mathrm{CD} 45^{+}\right)$within the lung cell suspension for standardization of hemacytometer counts.

\section{Flow Cytometry}

Standard methodology was employed for the direct immunofluorescence of pulmonary leukocytes $(25,41)$. Briefly, in 96-well U-bottom plates, $100 \mu \mathrm{l}$ containing $1 \times 10^{6}$ cells in PBS plus $2 \%$ FBS (FACS buffer) were incubated with Fcblock (BD Biosciences) diluted in FACS buffer for 5 min to block nonspecific binding of antibodies to cellular Fc receptors. An optimal concentration of fluorochrome-conjugated antibodies $\left(0.125-1 \mu \mathrm{g} / 1 \times 10^{6}\right.$ cells $)$ as listed in Table 1 was added in various combinations to allow for dual or triple staining, and cells were then incubated for $30 \mathrm{~min}$ at $4^{\circ} \mathrm{C}$. Cells were washed three times with FACS buffer and fixed in $200 \mu \mathrm{l}$ of $2 \%$ ultrapure formaldehyde (Polysciences) diluted in FACS buffer (fixation buffer). Cells analyzed for intracellular cytokine staining were fixed in fixation buffer for $10 \mathrm{~min}$ in the dark at room temp. The cells were then permeabilized with $0.1 \%$ saponin (diluted in FACS buffer) and incubated for $10 \mathrm{~min}$ in the dark at room temperature. Antibodies listed in 
Table 1 were subsequently added at optimal concentrations, and cells incubated at $4^{\circ} \mathrm{C}$ for $30 \mathrm{~min}$. Following incubation, cells were washed three times with $0.1 \%$ saponin buffer and resuspended in fixation buffer. Cells incubated with either FACS buffer alone or single fluorochrome-conjugated Abs were used to determine positive staining and spillover/compensation calculations, and background fluorescence determined with FlowJo Software (FlowJo, LLC, Ashland, OR, USA). Raw data were collected with the BD FACSArray flow cytometer (BD Biosciences) and then analyzed using FlowJo Software. Dead cells were excluded on the basis of forward angle and $90^{\circ}$ light scatter. For data analyses, 30,000 events (cells) were evaluated from a predominantly leukocyte population identified by back gating from $\mathrm{CD} 45^{+}$stained cells. The absolute number of total leukocytes was quantified by multiplying the total number of cells observed by hemacytometer counting by the percentage of $\mathrm{CD} 45^{+}$cells determined by flow cytometry. The absolute number of leukocytes (CD45 ${ }^{+}$cells), $\mathrm{T}$ cells $\left(\mathrm{CD} 4^{+} / \mathrm{CD}^{+}\right.$and $\mathrm{CD} 8^{+} /$ $\left.\mathrm{CD}^{+}\right), \mathrm{CD} 9^{+} / \mathrm{CD} 45^{+}, \mathrm{Ly}_{6 \mathrm{G}^{+}} / \mathrm{CD} 45^{+}, \mathrm{F} 4 / 80^{+} / \mathrm{CD} 45^{+}, \mathrm{CD} 11 \mathrm{~b}^{\mathrm{int}} /$

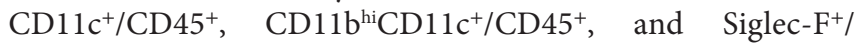
$\mathrm{CD} 1 \mathrm{~b}^{+}$was determined by multiplying the percentage of each gated population by the total number of $\mathrm{CD} 45^{+}$cells. Gating strategies are provided as supplemental materials. Intracellular cytokine staining is represented in histograms with unstained cells as a control.

\section{Statistical Analysis}

The unpaired Student's $t$ test (two-tailed) was used to analyze the immunization studies fungal burden, pulmonary cell populations, and cytokine/chemokine data where appropriate using GraphPad Prism version 5.00 for Windows (GraphPad Prism Software, San Diego, CA, USA). Survival data were analyzed using the log-rank test (GraphPad Software). Significant differences were defined as ${ }^{*} p<0.05,{ }^{* *} p<0.005$, or ${ }^{* * *} p<0.0001$.

\section{RESULTS}

\section{Immunization with C. neoformans Strain H99 Elicits Protection against Disparate Cryptococcus Serotypes}

Previous studies in our lab demonstrated that experimental pulmonary infection with C. neoformans strain H99 $\gamma$ in mice results in clearance of the acute infection and induction of protective immunity against a subsequent otherwise lethal challenge with a WT C. neoformans strain H99 that does not produce IFN- $\gamma$ $(25,36-40)$. Nevertheless, studies to date have not demonstrated that protective immunity generated against one serotype of Cryptococcus affords protection against multiple disparate Cryptococcus serotypes. Consequently, we sought to determine the level of cross-protection that is generated in mice immunized with $C$. neoformans strain $\mathrm{H} 99 \gamma$, a serotype A strain, against pulmonary infection with disparate serotypes of Cryptococcus. To establish a baseline prior to evaluating if immunization with Cryptococcus strain $\mathrm{H} 99 \gamma$, serotype A, enhanced protection against challenge with disparate Cryptococcus serotypes, we first determined the relative virulence of each serotype in nonimmunized mice. To do this, BALB/c mice were given an experimental pulmonary infection with either Cryptococcus strain H99 (serotype A), R265 (serotype B), WSA87 (serotype C), or R4247 (serotype D) and evaluated for mortality (Figure 1A). As shown in Figure 1A, experimental pulmonary infection with Cryptococcus strains H99, R265, and R4247 resulted in 100\% mortality with median survival times of 28,32 , and 33 days, respectively. In contrast, we observed $87.5 \%$ survival in mice given an experimental pulmonary infection with WSA87. Cryptococcus strain WSA87, serotype C, appeared to be significantly less virulent compared to all the other strains tested during our analysis.

Next, we tested the potential of mice immunized with C. neoformans strain H99 (serotype A) to be protected against challenge with Cryptococcus serotypes B, C, or D. For this, mice were immunized with $C$. neoformans strain $\mathrm{H} 99 \gamma$ or

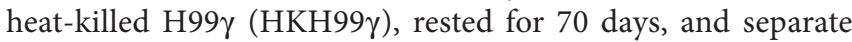
groups subsequently given an experimental pulmonary challenge with each Cryptococcus serotype. We observed a $100 \%$ survival rate in mice immunized with $\mathrm{H} 99 \gamma$ and challenged with $\mathrm{H} 99$, while the HKH99 $\gamma$ immunized mice challenged with $\mathrm{H} 99$ demonstrated a median survival time of 28 days post challenge (Figure 1B), confirming our previous observations $(38,40)$. Mice immunized with H99 $\gamma$ and then challenged with either R265 (C. gattii serotype B) or R4247 (C. deneoformans serotype D) exhibited median survival times of 59 and 72 days post challenge, respectively, and significantly increased survival rates compared to HKH99 $\gamma$ immunized mice challenged with the same strain (median survival of 33 and 34.5 days in R265 and R4247 challenged mice, respectively; Figure 1B). Additionally, we observed a $20 \%$ survival rate in protectively immunized mice challenged with R4247 at 100 days post challenge. Figure 1B shows that no significant difference in mortality was observed in H99y immunized mice challenged with WSA87 (median survival time of 90.5 days) compared to HKH99 $\gamma$ immunized mice challenged with the same strain (median survival time of 87.5 days). The mortality of mice immunized with $\mathrm{HKH} 99 \gamma$ and challenged with each Cryptococcus serotype mirrored the mortality rates of non-immunized mice given an experimental infection with each serotype and provided no additional protection (Figures 1A,B).

Pulmonary fungal burden was also quantified at days 3, 7, and 14 post challenge in H99 $\gamma$ or HKH99 $\gamma$ immunized mice challenged with each individual serotype (Figure 1C). Mice immunized with HKH99 $\gamma$ and challenged with each species showed progressive growth of each serotype in the lungs. In contrast, we observed significantly less pulmonary fungal burden as early as day 3 in H99 $\gamma$ immunized mice challenged with R265 and WSA87 compared to HKH99 $\gamma$ immunized mice (Figure 1C). Additionally, H99 immunized mice showed significantly less pulmonary fungal burden following challenge with all serotypes on days 7 and 14 post challenge compared to HKH99 $\gamma$ immunized mice challenged with the same strain. Brain fungal burden was also quantified at day 14 post challenge and a trend (although not statistically significant) toward a reduction of brain fungal burden together with the number of mice negative for Cryptococcus in the brain was observed in 


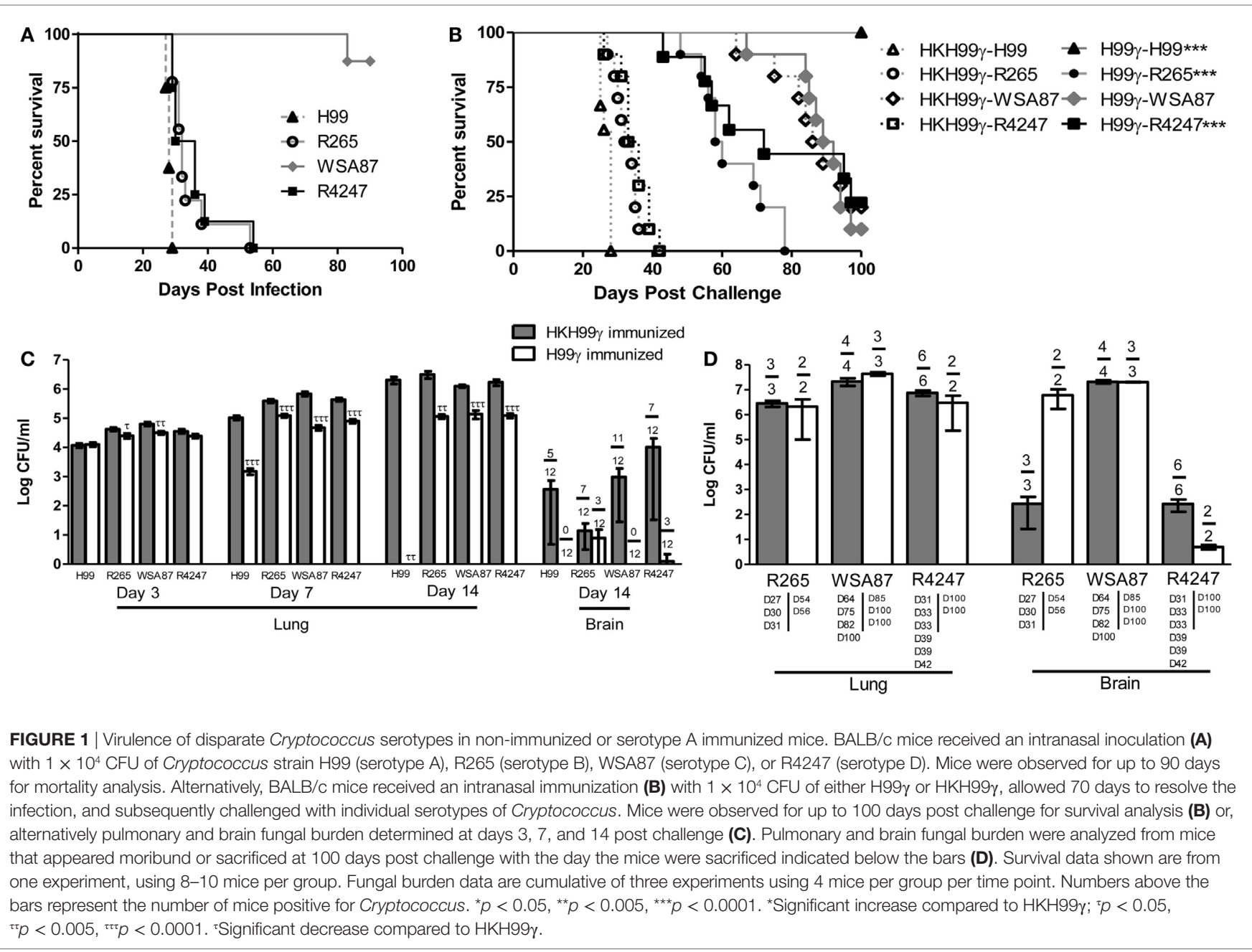

H99 $\gamma$ immunized mice challenged with each serotype compared to their HKH99 $\gamma$ immunized counterparts (Figure 1C). Overall, our data show that mice immunized with H99 $\gamma$, serotype A, display significant protection against challenge with serotypes A, $\mathrm{B}$, or D of Cryptococcus.

Figure 1D demonstrates the fungal burden of moribund mice or mice sacrificed at the conclusion of the study. The HKH99 $\gamma$ immunized mice challenged with R265 appeared to have similar pulmonary fungal burden and less brain fungal burden at time of death compared to H99 $\gamma$ immunized mice challenged with R265 (Figure 1D). No significant differences in pulmonary or brain fungal burden were observed between H99 $\gamma$ and HKH99 $\gamma$ immunized mice challenged with WSA87 (Figure 1D). Both groups of mice immunized with HKH99 $\gamma$ or H99 $\gamma$ and challenged with R4247 appear to have similar pulmonary fungal burden and lower brain fungal burden at sacrifice with the H99y immunized mice surviving longer. However, we cannot definitively state if the mice succumbed to pulmonary and/or brain fungal burden. Overall, immunization with $\mathrm{H} 99 \gamma$ appeared to prolong the survival of mice challenged with each serotype.

\section{Pulmonary Leukocyte Recruitment during Pulmonary Cryptococcosis Is Increased in H99 $\gamma$ Immunized Mice Challenged with Each Cryptococcus Serotype}

Our next goal was to examine the pulmonary inflammatory response in immunized mice during infection with the various representative Cryptococcus serotypes. We observed a significant increase in the total number of leukocytes recruited to the lungs of H99 $\gamma$ immunized mice challenged with $\mathrm{H} 99$ at days 3 and 7 post challenge compared to HKH99 $\gamma$ immunized mice (Figure 2A). Additionally, we observed significant increases in leukocyte recruitment to the lungs of H99 $\gamma$ immunized mice challenged with R265 on days 7 and 14 post challenge, H99 $\gamma$ immunized mice challenged with WSA87 on days 3 and 7 post challenge, and H99 $\gamma$ immunized mice challenged with R4247 at each time point post challenge compared to their HKH99 $\gamma$ immunized counterparts (Figure 2A). We observed an increased total cell number of $\mathrm{F} 4 / 80^{+}$cells in the lungs of H99 $\gamma$ immunized mice challenged with $\mathrm{H} 99$ at day 3, R4247 at days 3 and 7, and WSA87 at day 14 post challenge compared 
to HKH99 $\gamma$ immunized mice (Figure 2B). We observed a significant increase in the total number of CD $11 b^{\text {hi }} / C D 11 c^{+}$cells recruited to the lungs of $\mathrm{H} 99 \gamma$ immunized mice challenged with H99, WSA87, or R4247 at day 3, each serotype at day 7 post challenge, and in H99 $\gamma$ immunized mice challenged with WSA87 at day 14 post challenge compared to HKH99 $\gamma$ immunized mice challenged with the same serotype (Figure 2C). Figure 2C also shows a significant increase in the percentage

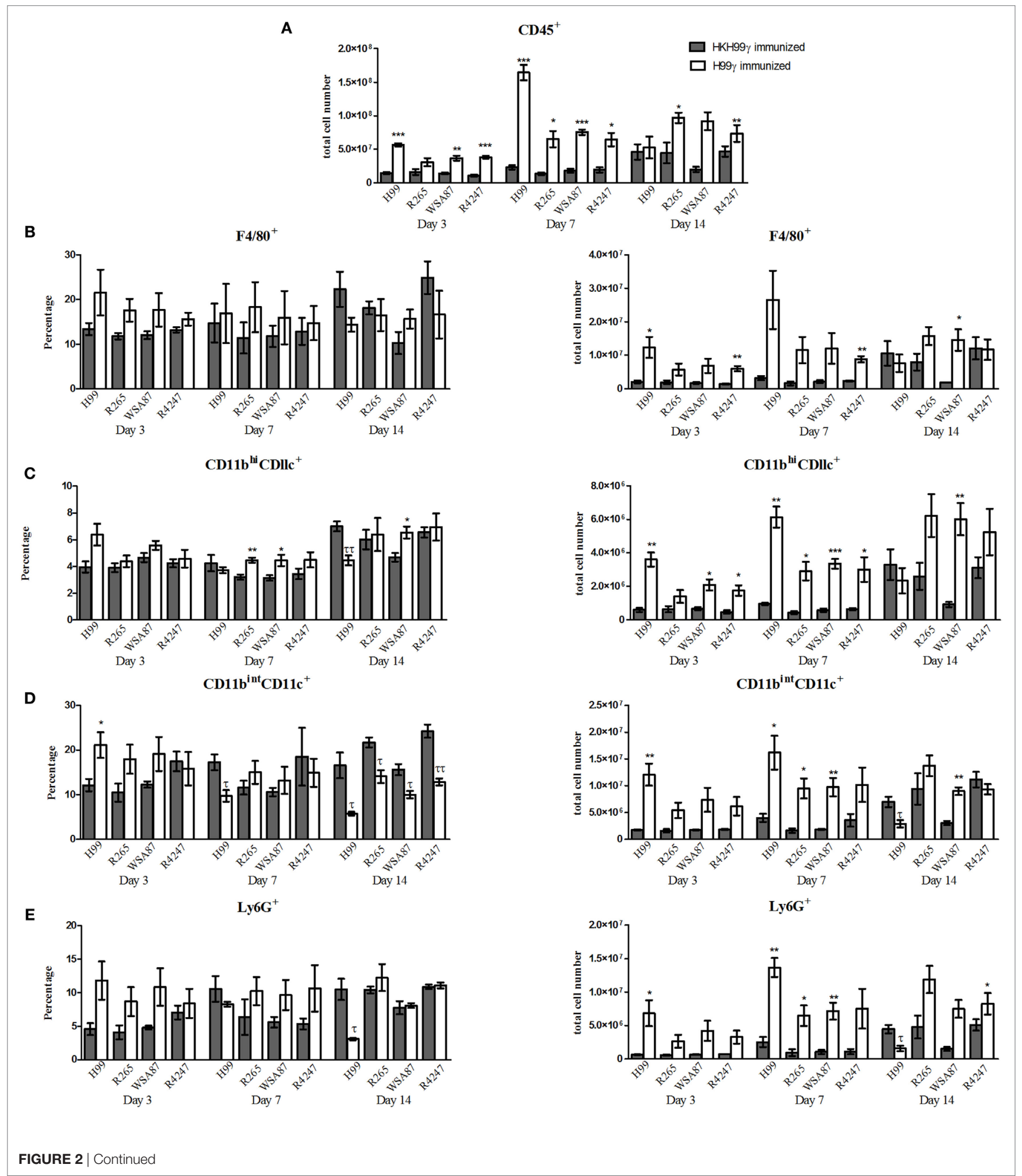



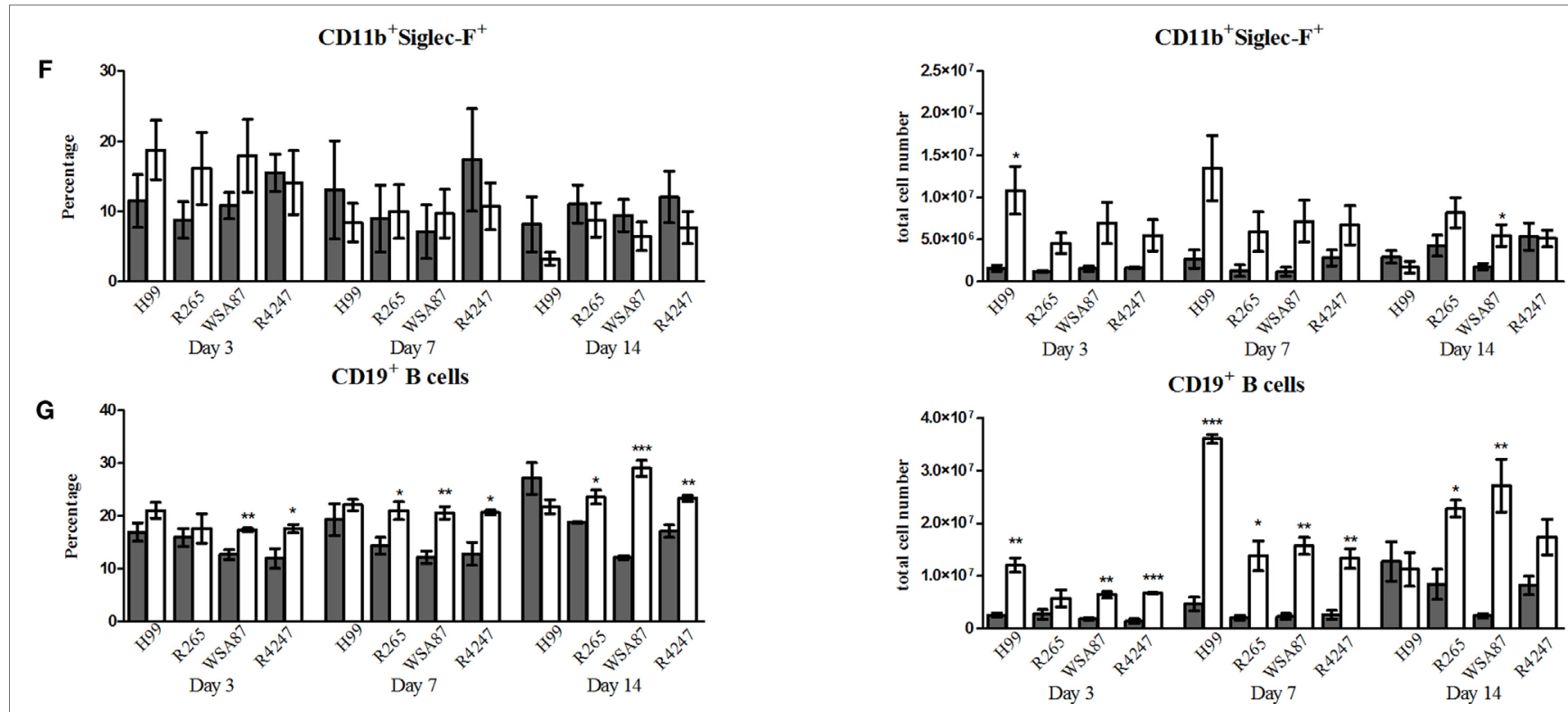

FIGURE 2 | Pulmonary leukocyte populations in immunized mice challenged with different serotypes of Cryptococcus. BALB/c mice were immunized intranasally

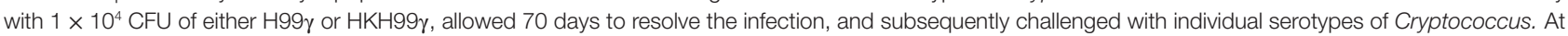
days 3,7 , and 14 post challenge, lungs were excised, tissues digested, and pulmonary infiltrates were analyzed by flow cytometry. Leukocytes were labeled with anti-CD45 (A) or dual labeled with anti-CD45 and antibodies for specific cell types (B-G) and analyzed by flow cytometry. Data shown are the mean \pm SEM of absolute cell numbers or percentage from three independent experiments performed using 4 mice per group per experiment. ${ }^{\star} p<0.05$, ${ }^{* \star} p<0.005$, ${ }^{\star \star \star} p<0.0001$.

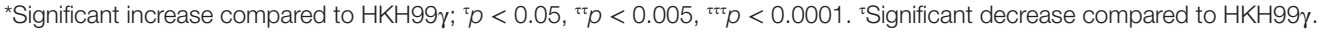

of CD $11 b^{\text {hi }} / \mathrm{CD} 11 \mathrm{c}^{+}$cells in H99 $\gamma$ immunized mice challenged with R265 or WSA 87 at day 7, and WSA87 at day 14 post challenge. There was also a significant increase in the total number of $\mathrm{CD} 11 \mathrm{~b}^{\text {int }} \mathrm{CD} 11 \mathrm{c}^{+}$cells in $\mathrm{H} 99 \gamma$ immunized mice challenged with H99 at days 3 and 7, R265 at day 7 post challenge, and WSA87 at days 7 and 14 post challenge (Figure 2D). Figure 2D also shows a significant increase in $\mathrm{CD} 11 \mathrm{~b}^{\text {int }} \mathrm{CD} 11 \mathrm{c}^{+}$cells in H99 $\gamma$ immunized mice challenged with H99 at day 3, while we observe a significant decrease in these cells at day 7 in H99 challenged mice, and across each serotype at day 14 post challenge. The recruitment of $\mathrm{Ly} 6 \mathrm{G}^{+}$cells to the lungs was significantly higher in $\mathrm{H} 99 \gamma$ immunized mice challenged with H99 at days 3 and 7 post challenge, R265 or WSA87 at day 7 post challenge, and in H99 $\gamma$ immunized mice challenged with R4247 on day 14 post challenge compared to their HKH99 immunized counterparts (Figure 2E). While mice immunized with $\mathrm{H} 99 \gamma$ and challenged with $\mathrm{H} 99$ are clearing the infection, these mice show a significant decrease in the total number and percentage of $\mathrm{Ly}_{6 \mathrm{G}^{+}}$cells at day 14 post infection compared to HKH99 $\gamma$ immunized mice (Figure 2E). We observed a significant increase in the total number of Siglec- $\mathrm{F}^{+}$cells in mice immunized with H99 $\gamma$ and challenged with H99 at day 3 post challenge and WSA87 challenged mice at day 14 post challenge (Figure 2F). We observed a significant increase in the total number of B cells in mice immunized with $\mathrm{H} 99 \gamma$ and challenged with H99, WSA87, or R4247 at day 3 post challenge, across each serotype at day 7 post challenge, and R265 or WSA87 at day 14 post challenge (Figure 2G). For the percentage of $\mathrm{B}$ cells, we observed a significant increase in H99 immunized mice challenged with WSA87 or R4247 across each time point and in mice challenged with R265 at days 7 and 14 post challenge (Figure 2G). Overall, our data show significantly increased pulmonary recruitment of $\mathrm{F} 4 / 80^{+}$ cells, CD $11 b^{+} / \mathrm{CD} 11 \mathrm{c}^{+}$cells, B cells, and $\mathrm{Ly} 6 \mathrm{G}^{+}$cells in mice immunized with the serotype A Cryptococcus strain $\mathrm{H} 99 \gamma$ following challenge with various other Cryptococcus serotypes which, altogether, may contribute to the increased protective responses observed in these mice.

\section{Immunization with $\mathrm{H} 99 \gamma$ Elicits Elevated Proinflammatory and a Predominant Th1-Type Cytokine Response following Challenge with Disparate Cryptococcus Serotypes}

The pulmonary fungal burden and mortality analysis suggested that mice immunized with H99 $\gamma$ were able to mount protective responses against challenge with disparate Cryptococcus serotypes. Therefore, we evaluated cytokine levels in the lungs of H99 $\gamma$ or HKH99 $\gamma$ immunized mice following challenge with each Cryptococcus serotype. Lung homogenates were prepared from pulmonary tissues of mice on days 3, 7, and 14 post challenge with Cryptococcus serotypes A, B, C, or D, and the levels of Th1 associated (IFN- $\gamma$, IL-2, IL-12p70), Th2 associated (IL-4 and IL-5), immunoregulatory (IL-10 and G-CSF), and proinflammatory (IL- $1 \alpha$, IL- $1 \beta$, IL-17A, and TNF- $\alpha$ ) cytokines and chemokines (CCL3, CCL4, CCL2, CXCL1, and CCL5) were determined. We observed that H99 $\gamma$ immunized 
mice challenged with $C$. neoformans strain H99 exhibited a significant increase in Th1 associated cytokines (IFN- $\gamma$, IL-2, and IL-12p70) as early as day 3 post challenge that remained significantly elevated, except IL-2, through day 7 post challenge compared to HKH99 $\gamma$ immunized mice challenged with H99 (Tables 2 and 3). However, we observed significantly less Th1 associated cytokine (IL-12p70 and IFN- $\gamma$ ) production at day 14 post challenge in $\mathrm{H} 99 \gamma$ immunized mice compared to HKH99 $\gamma$ immunized mice (Table 4). Also, proinflammatory (IL- $1 \alpha$ and IL-1 $\beta$ ) and immunoregulatory (G-CSF) cytokines and chemokine levels (CCL3, CCL4, CCL2, and CXCL1) in H99 $\gamma$ immunized mice challenged with H99 were significantly less compared to levels observed in HKH99 $\gamma$ immunized mice challenged with H99 at day 14 post challenge (Table 4). The significant decrease in Th1 associated and proinflammatory cytokine and chemokine levels in H99y immunized mice challenged with $\mathrm{H} 99$ at day 14 post challenge compared to levels observed in HKH99 $\gamma$ immunized mice likely coincides with the significant reduction in pulmonary fungal burden observed in the H99 $\gamma$ immunized mice; whereas, the HKH99 $\gamma$ immunized mice are experiencing progressive disease (Figure 1C). Th1 associated cytokine levels in the lungs of H99 $\gamma$ immunized mice challenged with each other serotype were generally elevated at day 3 post challenge and remained significantly elevated at days 7 and 14 post challenge, particularly cytokines IFN- $\gamma$ and IL-12p70, compared to their HKH99 $\gamma$ immunized counterparts (Tables 2-4). For Th2-associated cytokines, we observed a significant increase at day 3 post challenge in mice that were immunized with $\mathrm{H} 99 \gamma$ and challenged with each serotype [H99 (IL-4 and IL-5), R265, WSA87, or R4247 (IL-5)] (Table 2). At day 7 post challenge in mice immunized with H99 $\gamma$, we observed an increase in IL-4 in mice challenged with R265 or R4247 (Table 3). By day 14 post challenge, there was a statistically significant decrease in Th2 associated cytokines (IL-4 and IL-5) across each serotype except for WSA87 challenged mice that showed significantly increased IL-5 levels across days 7 and 14 post challenge (Tables 3 and 4). We also observed an overall trend toward significantly increased proinflammatory cytokine (IL-1 $\alpha$, IL-1 $\beta$, and IL-17A), immunoregulatory cytokine (G-CSF), and chemokine (CCL3, CCL4, CCL2, CXCL1, and CCL5) production as early as day 3 post challenge that remained elevated through day 7 post challenge in H99 $\gamma$ immunized mice challenged with each serotype compared to similarly challenged mice immunized using HKH99 $\gamma$ (Tables 2 and 3). We observed an overall trend toward significantly higher levels of proinflammatory cytokine (IL-1 $\alpha$, IL-1 $\beta$, IL-17A, and TNF- $\alpha$ ), immunoregulatory cytokine (G-CSF), and chemokine levels (CCL3, CCL4, CCL2, CXCL1, and RANTES) was observed in H99 $\gamma$ immunized mice challenged with R265, WSA87, or R4247 compared to similarly challenged HKH99 $\gamma$ immunized at day 14 post challenge except for CCL3 and CXCL1 for R265 challenged mice, and CCL3 and CCL2 for R4247 challenged mice (Table 4). Altogether, the cytokine results suggest that immunization with $C$. neoformans strain $\mathrm{H} 99 \gamma$ elicits a heightened cytokine anamnestic response against multiple disparate serotypes of Cryptococcus compared to HKH99 $\gamma$ immunized mice.

\section{Vaccine-Mediated Protection against Pulmonary Cryptococcosis Is Associated with Enhanced Th1-Type Immune Responses}

We next evaluated $\mathrm{T}$ cell responses in the lungs of immunized mice following challenge with the various Cryptococcus serotypes. Flow cytometry analysis was utilized to determine levels of $\mathrm{CD} 4^{+}$ and $\mathrm{CD}^{+} \mathrm{T}$ cell infiltration to the lungs on days 3,7 , and 14 post challenge. Also, intracellular cytokine staining of $\mathrm{CD} 4^{+} \mathrm{T}$ cells for representative Thelper (Th) 1, Th2, and Th17-type cytokines IFN$\gamma$, IL-4, and IL-17A, respectively, and subsequent flow cytometry analysis was used to access the $\mathrm{CD} 4^{+}$Th cell phenotype during the anamnestic response to pulmonary cryptococcosis. We observed an overall trend toward increased total numbers of $\mathrm{CD}^{+}$and $\mathrm{CD}^{+} \mathrm{T}$ cells in H99 $\gamma$ immunized mice compared to HKH99 $\gamma$ immunized mice following challenge with each serotype as the infection progressed (Figures 3A,B). The total number of $\mathrm{CD}^{+}$ T cells was significantly increased in H99 $\gamma$ immunized mice challenged with H99, R265, or R4247 at day 3 post challenge, and in mice challenged with $\mathrm{H} 99$ at day 7 post challenge compared to their HKH99 $\gamma$ immunized counterparts (Figure 3A). However, there was no significant difference in percentage of $\mathrm{CD} 4^{+} \mathrm{T}$ cells between groups. We also observed an increase in the total number of $\mathrm{CD}^{+} \mathrm{T}$ cells in $\mathrm{H} 99 \gamma$ immunized mice challenged with $\mathrm{H} 99$, WSA87, or R4247 at day 3 post challenge, in mice challenged with H99, R265, or WSA87 at day 7 post challenge, and in R265 or WSA87 challenged mice at day 14 post challenge compared to HKH99 $\gamma$ immunized mice challenged with their equivalent serotype (Figure 3B). A significant increase in the percentage of $\mathrm{CD}^{+} \mathrm{T}$ cells was observed in mice immunized with H99 $\gamma$ and challenged with R265 or R4247 at day 14 post challenge compared to their HKH99 $\gamma$ immunized counterparts.

Overall, we observed significant increases in the total number of $\mathrm{CD}^{+} / \mathrm{IFN}-\gamma^{+} \mathrm{T}$ cells followed by $\mathrm{CD} 4^{+} / \mathrm{IL}-17 \mathrm{~A}^{+} \mathrm{T}$ cells and then $\mathrm{CD} 4^{+} / \mathrm{IL}-4^{+} \mathrm{T}$ cells at day 7 post challenge in $\mathrm{H} 99 \gamma$ immunized mice challenged with each serotype compared to HKH99 $\gamma$ immunized mice challenged with the corresponding serotype (Figures 3C-E). We observed greater total CD4 $4^{+} / \mathrm{IFN}-\gamma^{+} \mathrm{T}$ cell numbers in H99 $\gamma$ immunized mice challenged with $\mathrm{H} 99$ compared to H99 $\gamma$ immunized mice challenged with R265, WSA87, or R4247 at day 7 post challenge (Figure 3C). These results suggest that mice immunized with $\mathrm{H} 99 \gamma$ are capable of eliciting a predominantly Th1-type anamnestic response upon challenge with each disparate Cryptococcus serotype. These data show that mice immunized with the serotype A strain exhibit an increased putatively protective Th1-type immune response following challenge with other disparate serotypes.

\section{Protection Afforded by Immunization with H99 $\gamma$ against Serotypes B and D of Cryptococcus Requires CD4 ${ }^{+}$T Cells}

Previous studies in our lab demonstrated that H99 $\gamma$ immunized mice depleted of $\mathrm{CD} 4^{+}$or $\mathrm{CD} 8^{+} \mathrm{T}$ cells were completely protected against an otherwise lethal challenge with the non-IFN- $\gamma$ producing C. neoformans strain H99 (40). Also, H99 immunized 
TABLE 2 | Cytokine levels within lung homogenates of H99 and HKH99y immunized mice infected with each serotype.

\begin{tabular}{|c|c|c|c|c|c|c|c|c|}
\hline \multicolumn{9}{|c|}{ Day 3 post challenge } \\
\hline & НКН99 $\gamma$ & $\mathrm{H} 99 \gamma$ & 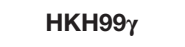 & $\mathrm{H} 99 \gamma$ & 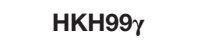 & $\mathrm{H} 99 \gamma$ & 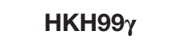 & H99 \\
\hline & \multicolumn{2}{|r|}{ H99 } & \multicolumn{2}{|c|}{ R265 } & \multicolumn{2}{|c|}{ WSA87 } & \multicolumn{2}{|c|}{ R4247 } \\
\hline \multicolumn{9}{|l|}{ Th1 associated } \\
\hline Interferon (IFN)- $\gamma$ & $5.88 \pm 1.45$ & $12.57 \pm 1.84^{\star}$ & $4.26 \pm 1.07$ & $6.461 \pm 0.9474$ & $5.59 \pm 1.55$ & $5.94 \pm 0.68$ & $3.22 \pm 0.71$ & $6.40 \pm 0.89^{\star}$ \\
\hline $\mathrm{IL}-2$ & $26.03 \pm 6.49$ & $109.30 \pm 18.96^{\star \star}$ & $17.98 \pm 3.66$ & $21.3 \pm 2.35$ & $22.15 \pm 6.41$ & $35.64 \pm 4.94$ & $15.09 \pm 3.28$ & $27.58 \pm 4.31^{\star}$ \\
\hline IL-12p70 & $13.51 \pm 0.72$ & $69.90 \pm 8.56^{\star \star \star}$ & $14.95 \pm 0.58$ & $27.9 \pm 1.754^{\star \star \star}$ & $16.04 \pm 4.42$ & $34.21 \pm 3.23^{\star \star}$ & $9.91 \pm 1.08$ & $29.20 \pm 3.97^{\star \star \star}$ \\
\hline \multicolumn{9}{|l|}{ Th2 associated } \\
\hline $\mathrm{IL}-4$ & $4.15 \pm 1.40$ & $34.58 \pm 6.29^{\star \star \star}$ & $4.36 \pm 1.33$ & $5.873 \pm 1.514$ & $4.58 \pm 1.31$ & $9.25 \pm 2.39$ & $4.22 \pm 1.27$ & $6.02 \pm 1.42$ \\
\hline IL-5 & $2.49 \pm 0.24$ & $10.96 \pm 0.94^{\star \star \star}$ & $2.26 \pm 0.30$ & $4.729 \pm 0.4244^{\star \star \star}$ & $2.91 \pm 0.63$ & $6.32 \pm 0.52^{\star \star \star}$ & $2.00 \pm 0.19$ & $5.43 \pm 0.27^{\star \star \star}$ \\
\hline \multicolumn{9}{|l|}{ Proinflammatory } \\
\hline $\mathbb{I L}-1 \alpha$ & $142.40 \pm 25.02$ & $20.86 \pm 3.38^{\tau \tau \tau}$ & $16.60 \pm 1.85$ & $18.53 \pm 0.9751$ & $18.45 \pm 3.08$ & $37.21 \pm 4.70^{\star \star}$ & $15.58 \pm 1.69$ & $23.42 \pm 2.61^{\star}$ \\
\hline $\mathrm{IL}-1 \beta$ & $45.79 \pm 4.72$ & $815.70 \pm 124.40^{\star \star \star}$ & $46.04 \pm 6.80$ & $105.9 \pm 8.724^{\star \star \star}$ & $45.37 \pm 2.90$ & $248.90 \pm 40.52^{\star \star \star}$ & $37.11 \pm 1.94$ & $120.40 \pm 18.97^{\star \star \star}$ \\
\hline IL-17A & $2.56 \pm 0.41$ & $501.70 \pm 83.71^{\star \star \star}$ & $2.72 \pm 0.25$ & $44.56 \pm 8.306^{\star \star \star}$ & $3.09 \pm 0.44$ & $195.50 \pm 43.31^{\star \star \star}$ & $2.41 \pm 0.30$ & $52.92 \pm 12.55^{\star \star}$ \\
\hline TNF- $\alpha$ & $45.64 \pm 5.51$ & $64.35 \pm 7.17$ & $40.39 \pm 4.26$ & $48.37 \pm 3.266$ & $38.08 \pm 4.85$ & $53.17 \pm 4.03^{\star}$ & $30.81 \pm 2.78$ & $48.19 \pm 4.99^{\star \star}$ \\
\hline \multicolumn{9}{|c|}{ Immunoregulatory } \\
\hline IL-10 & $5.15 \pm 0.61$ & $23.05 \pm 1.96^{\star \star \star}$ & $4.25 \pm 0.76$ & $11.18 \pm 1.105^{\star \star \star}$ & $4.30 \pm 0.51$ & $12.78 \pm 0.81^{\star \star \star}$ & $3.93 \pm 0.55$ & $8.90 \pm 1.09^{\star \star}$ \\
\hline G-CSF & $5.22 \pm 1.25$ & $510.90 \pm 64.82^{\star \star \star}$ & $5.27 \pm 1.19$ & $45.88 \pm 5.85^{\star \star \star}$ & $5.62 \pm 1.30$ & $135.90 \pm 24.62^{\star \star \star}$ & $4.76 \pm 1.21$ & $64.73 \pm 12.34^{\star \star \star}$ \\
\hline \multicolumn{9}{|l|}{ Chemokine } \\
\hline CCL3/MIP-1 $\alpha$ & $43.41 \pm 5.17$ & $452.80 \pm 49.90^{\star \star \star}$ & $45.01 \pm 3.49$ & $111.60 \pm 9.96^{\star \star \star}$ & $68.20 \pm 24.17$ & $194.70 \pm 18.11^{\star \star \star}$ & $37.94 \pm 1.68$ & $122.20 \pm 12.11^{\star \star \star}$ \\
\hline CCL4/MIP-1 $\beta$ & $6.64 \pm 0.81$ & $79.97 \pm 13.09^{\star \star \star}$ & $6.27 \pm 0.53$ & $16.58 \pm 1.97^{\star \star \star}$ & $6.35 \pm 0.70$ & $35.92 \pm 6.91^{\star \star \star}$ & $4.72 \pm 0.21$ & $17.78 \pm 1.94^{\star \star \star}$ \\
\hline CCL2/MCP-1 & $57.51 \pm 8.79$ & $934.30 \pm 88.77^{\star \star \star}$ & $64.73 \pm 4.93$ & $189.30 \pm 21.11^{\star \star \star}$ & $64.70 \pm 6.91$ & $411.70 \pm 95.02^{\star \star}$ & $56.65 \pm 6.29$ & $183.00 \pm 17.56^{\star \star \star}$ \\
\hline CXCL1/KC & $26.76 \pm 1.74$ & $971.50 \pm 94.97^{\star \star \star}$ & $34.39 \pm 4.76$ & $189.70 \pm 31.80^{\star \star \star}$ & $32.66 \pm 2.49$ & $460.40 \pm 79.29^{\star \star \star}$ & $26.03 \pm 1.98$ & $211.60 \pm 31.00^{\star \star \star}$ \\
\hline CCL5/RANTES & $152.90 \pm 19.47$ & $1241.00 \pm 127.50^{\star \star \star}$ & $166.60 \pm 11.56$ & $321.00 \pm 42.19^{\star \star}$ & $273.70 \pm 118.80$ & $560.70 \pm 49.99^{\star}$ & $156.00 \pm 10.44$ & $375.60 \pm 38.23^{\star \star \star}$ \\
\hline
\end{tabular}

Data shown are expressed as mean \pm SEM and are cumulative of three experiments using four mice per group per time point.

Bolded values indicate significance either increased or decreased compared to HKH99\%.

${ }^{*} p<0.05,{ }^{* *} p<0.005,{ }^{* * *} p<0.0001$ significant increase compared to HKH99\%.

${ }^{\tau \pi t} p<0.0001$ significant decrease compared to HKH99\%. 
TABLE 3 | Cytokine levels within lung homogenates of H99y and HKH99y immunized mice infected with each serotype.

\begin{tabular}{|c|c|c|c|c|c|c|c|c|}
\hline \multicolumn{9}{|c|}{ Day 7 post challenge } \\
\hline & НКН99 & H99 & НКH99 & H99ү & НКН99 & $\mathrm{H} 99 \gamma$ & 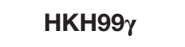 & $\mathrm{H} 99 \gamma$ \\
\hline & \multicolumn{2}{|r|}{ H99 } & \multicolumn{2}{|r|}{ R265 } & \multicolumn{2}{|r|}{ WSA87 } & \multicolumn{2}{|c|}{ R4247 } \\
\hline \multicolumn{9}{|l|}{ Th1 associated } \\
\hline $\mathrm{IFN}-\gamma$ & $5.23 \pm 0.79$ & $13.28 \pm 0.88^{\star \star \star}$ & $4.83 \pm 0.54$ & $10.36 \pm 1.08^{\star \star \star}$ & $5.29 \pm 0.95$ & $10.40 \pm 0.42^{\star \star \star}$ & $5.70 \pm 1.46$ & $9.61 \pm 0.62^{\star}$ \\
\hline $\mathrm{IL}-2$ & $19.69 \pm 5.12$ & $31.41 \pm 3.14$ & $24.52 \pm 8.36$ & $35.83 \pm 4.22$ & $20.02 \pm 4.53$ & $37.75 \pm 5.55^{\star}$ & $24.48 \pm 6.46$ & $38.61 \pm 4.57$ \\
\hline IL-12p70 & $27.22 \pm 5.78$ & $139.60 \pm 30.20^{\star *}$ & $14.19 \pm 3.31$ & $77.97 \pm 15.14^{\star \star}$ & $13.12 \pm 2.53$ & $75.36 \pm 5.15^{\star \star \star}$ & $16.58 \pm 4.11$ & $61.84 \pm 6.50^{\star \star \star}$ \\
\hline \multicolumn{9}{|l|}{ Th2 associated } \\
\hline $\mathrm{IL}-4$ & $30.90 \pm 14.04$ & $12.87 \pm 3.31$ & $1.98 \pm 1.30$ & $8.46 \pm 1.58^{\star \star}$ & $0.33 \pm 0.12$ & $5.19 \pm 2.53$ & $0.45 \pm 0.16$ & $4.86 \pm 1.29^{\star \star}$ \\
\hline IL-5 & $12.51 \pm 2.74$ & $8.41 \pm 0.72$ & $8.08 \pm 2.36$ & $6.89 \pm 0.39$ & $0.96 \pm 0.37$ & $5.73 \pm 1.47^{\star \star}$ & $7.05 \pm 0.83$ & $6.97 \pm 1.16$ \\
\hline \multicolumn{9}{|c|}{ Proinflammatory } \\
\hline $\mid \mathrm{L}-1 \alpha$ & $31.91 \pm 5.40$ & $353.40 \pm 95.66^{\star \star}$ & $20.30 \pm 5.94$ & $109.40 \pm 17.98^{\star \star \star}$ & $15.39 \pm 1.78$ & $152.30 \pm 35.52^{\star \star}$ & $18.42 \pm 2.24$ & $95.36 \pm 17.63^{\star \star \star}$ \\
\hline IL-1 $\beta$ & $123.10 \pm 23.21$ & $1816.00 \pm 409.20^{\star \star}$ & $46.24 \pm 4.47$ & $782.00 \pm 137.60^{\star \star \star \star}$ & $29.71 \pm 3.71$ & $942.80 \pm 206.40^{\star \star \star *}$ & $49.95 \pm 7.70$ & $647.60 \pm 121.60^{\star \star \star}$ \\
\hline IL-17A & $6.84 \pm 2.27$ & $663.20 \pm 90.46^{\star \star \star}$ & $0.62 \pm 0.24$ & $454.60 \pm 83.45^{\star \star \star}$ & $0.47 \pm 0.18$ & $669.40 \pm 210.30^{\star \star}$ & $0.77 \pm 0.23$ & $481.50 \pm 112.00^{\star \star \star}$ \\
\hline TNF- $\alpha$ & $39.17 \pm 3.51$ & $84.68 \pm 5.97^{\star \star \star}$ & $34.34 \pm 1.70$ & $66.83 \pm 3.35^{\star \star \star}$ & $37.01 \pm 3.59$ & $66.90 \pm 3.61^{\star \star \star}$ & $40.08 \pm 4.15$ & $59.52 \pm 3.14^{\star \star}$ \\
\hline \multicolumn{9}{|c|}{ Immunoregulatory } \\
\hline IL-10 & $7.31 \pm 0.84$ & $40.08 \pm 5.68^{\star \star \star}$ & $5.30 \pm 0.92$ & $25.05 \pm 3.14^{\star \star \star}$ & $4.02 \pm 0.51$ & $27.08 \pm 2.55^{\star \star \star}$ & $3.87 \pm 0.78$ & $21.09 \pm 2.47^{\star \star \star}$ \\
\hline G-CSF & $64.74 \pm 13.03$ & $408.90 \pm 99.61^{\star \star}$ & $5.92 \pm 0.85$ & $211.10 \pm 44.00^{\star \star \star}$ & $3.22 \pm 0.34$ & $298.50 \pm 89.68^{\star \star}$ & $13.12 \pm 2.22$ & $189.40 \pm 53.74^{\star \star}$ \\
\hline \multicolumn{9}{|l|}{ Chemokine } \\
\hline CCL3/MIP-1 $\alpha$ & $138.00 \pm 31.56$ & $354.40 \pm 36.93^{\star \star \star}$ & $44.37 \pm 3.16$ & $226.90 \pm 15.24^{\star \star \star}$ & $29.94 \pm 2.05$ & $255.40 \pm 53.29^{\star \star \star}$ & $34.75 \pm 5.91$ & $207.70 \pm 37.53^{\star \star \star}$ \\
\hline CCL4/MIP-1 $\beta$ & $29.95 \pm 6.78$ & $66.32 \pm 14.73^{\star}$ & $8.82 \pm 1.72$ & $40.40 \pm 4.68^{\star \star \star}$ & $6.86 \pm 1.17$ & $43.55 \pm 6.54^{\star \star \star}$ & $6.77 \pm 1.42$ & $31.96 \pm 3.67^{\star \star \star}$ \\
\hline CCL2/MCP-1 & $372.60 \pm 95.97$ & $962.50 \pm 152.70^{\star \star}$ & $89.06 \pm 14.96$ & $713.00 \pm 127.20^{\star \star \star}$ & $38.46 \pm 5.58$ & $636.00 \pm 64.17^{\star \star \star}$ & $116.90 \pm 28.72$ & $474.90 \pm 58.73^{\star \star \star}$ \\
\hline $\mathrm{CXCL} 1 / \mathrm{KC}$ & $268.20 \pm 47.52$ & $1055.00 \pm 169.70^{\star \star \star \star}$ & $58.81 \pm 7.29$ & $774.70 \pm 118.20^{\star \star \star}$ & $45.73 \pm 14.61$ & $782.60 \pm 140.60^{\star \star \star}$ & $86.95 \pm 15.98$ & $643.10 \pm 111.40^{\star \star \star}$ \\
\hline CCL5/RANTES & $246.70 \pm 31.91$ & $1407.00 \pm 156.60^{\star \star \star ~}$ & $135.20 \pm 6.51$ & $621.90 \pm 59.09^{\star \star \star}$ & $105.80 \pm 8.11$ & $880.10 \pm 183.90^{\star \star \star}$ & $86.45 \pm 11.71$ & $607.50 \pm 110.20^{\star \star \star}$ \\
\hline
\end{tabular}

Data shown are expressed as mean \pm SEM and are cumulative of three experiments using four mice per group per time point.

Bolded values indicate significance either increased or decreased compared to HKH99.

${ }^{*} p<0.05,{ }^{* *} p<0.005,{ }^{* *} p<0.0001$ significant increase compared to HKH99y 
TABLE 4 | Cytokine levels within lung homogenates of H99y and HKH99y immunized mice infected with each serotype.

\begin{tabular}{|c|c|c|c|c|c|c|c|c|}
\hline \multicolumn{9}{|c|}{ Day 14 post challenge } \\
\hline & 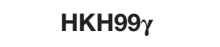 & $\mathrm{H} 99 \gamma$ & 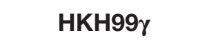 & H99 & 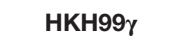 & $\mathrm{H} 99 \gamma$ & HКH99 & $\mathrm{H} 99 \gamma$ \\
\hline & \multicolumn{2}{|c|}{ H99 } & \multicolumn{2}{|c|}{ R265 } & \multicolumn{2}{|r|}{ WSA87 } & \multicolumn{2}{|c|}{ R4247 } \\
\hline \multicolumn{9}{|l|}{ Th1 associated } \\
\hline $\mathrm{IFN}-\gamma$ & $8.37 \pm 0.60$ & $6.33 \pm 0.54^{\tau}$ & $7.09 \pm 0.74$ & $11.71 \pm 0.88^{\star \star}$ & $4.61 \pm 0.57$ & $10.52 \pm 0.66^{\star \star \star}$ & $4.80 \pm 0.23$ & $10.82 \pm 0.94^{\star \star \star}$ \\
\hline IL-2 & $15.67 \pm 1.19$ & $15.87 \pm 3.17$ & $14.14 \pm 0.43$ & $28.83 \pm 2.17^{\star \star \star}$ & $13.21 \pm 4.47$ & $28.20 \pm 1.48^{\star \star}$ & $9.67 \pm 1.21$ & $28.49 \pm 1.09^{\star \star \star}$ \\
\hline IL-12p70 & $78.16 \pm 10.72$ & $30.11 \pm 2.46^{\tau \tau \tau}$ & $62.74 \pm 9.46$ & $130.30 \pm 23.33^{\star}$ & $21.28 \pm 2.23$ & $127.10 \pm 20.38^{\star \star \star}$ & $41.41 \pm 3.31$ & $135.10 \pm 21.07^{\star \star \star}$ \\
\hline \multicolumn{9}{|l|}{ Th2 associated } \\
\hline $\mathrm{IL}-4$ & $190.30 \pm 33.23$ & $1.37 \pm 0.37^{\tau \tau}$ & $102.40 \pm 17.90$ & $14.11 \pm 4.43^{\tau \tau \tau}$ & $6.38 \pm 2.57$ & $4.96 \pm 0.96$ & $68.98 \pm 7.51$ & $12.23 \pm 2.89^{\tau \tau \tau}$ \\
\hline IL-5 & $23.74 \pm 5.57$ & $1.83 \pm 0.70^{\tau \tau}$ & $73.75 \pm 21.66$ & $8.24 \pm 0.98^{\tau \tau}$ & $4.95 \pm 1.27$ & $8.88 \pm 1.09^{\star}$ & $74.35 \pm 13.94$ & $7.35 \pm 0.86^{\tau \tau \tau}$ \\
\hline \multicolumn{9}{|c|}{ Proinflammatory } \\
\hline $\mid \mathrm{L}-1 \alpha$ & $151.60 \pm 18.96$ & $20.36 \pm 2.50^{\tau \tau \tau}$ & $122.20 \pm 12.17$ & $380.80 \pm 84.73^{\star \star}$ & $29.50 \pm 6.28$ & $337.90 \pm 46.85^{\star \star \star}$ & $105.90 \pm 14.39$ & $471.00 \pm 39.58^{\star \star \star}$ \\
\hline IL-1 $\beta$ & $862.80 \pm 218.50$ & $87.04 \pm 8.71^{\tau \tau}$ & $398.20 \pm 71.61$ & $2434.00 \pm 519.10^{\star \star}$ & $82.79 \pm 21.65$ & $2346.00 \pm 383.20^{\star \star \star}$ & $315.20 \pm 53.03$ & $2645.00 \pm 322.50^{\star \star \star \star}$ \\
\hline IL-17A & $55.84 \pm 10.26$ & $33.87 \pm 6.83$ & $17.10 \pm 4.86$ & $959.40 \pm 178.60^{\star \star \star}$ & $3.24 \pm 1.27$ & $897.10 \pm 105.60^{\star \star \star}$ & $6.65 \pm 2.03$ & $968.90 \pm 83.29^{\star \star \star}$ \\
\hline TNF- $\alpha$ & $52.10 \pm 2.22$ & $46.05 \pm 3.00$ & $45.81 \pm 2.05$ & $80.03 \pm 6.04^{\star \star \star}$ & $32.51 \pm 2.89$ & $76.46 \pm 4.20^{\star \star \star}$ & $38.77 \pm 1.57$ & $71.21 \pm 4.29^{\star \star \star}$ \\
\hline \multicolumn{9}{|c|}{ Immunoregulatory } \\
\hline $\mid \mathrm{L}-10$ & $26.14 \pm 1.78$ & $11.61 \pm 0.93^{\tau \tau \tau}$ & $27.59 \pm 3.00$ & $40.29 \pm 4.54^{\star}$ & $7.96 \pm 0.98$ & $39.11 \pm 3.23^{\star \star \star}$ & $17.97 \pm 1.63$ & $40.08 \pm 3.30^{\star \star \star}$ \\
\hline G-CSF & $62.52 \pm 15.47$ & $5.02 \pm 0.42^{\tau \tau}$ & $42.48 \pm 4.68$ & $81.41 \pm 13.82^{\star}$ & $13.80 \pm 2.37$ & $110.50 \pm 20.14^{\star \star \star}$ & $35.52 \pm 4.65$ & $88.34 \pm 10.39^{\star \star \star}$ \\
\hline \multicolumn{9}{|l|}{ Chemokine } \\
\hline CCL3/MIP-1 $\alpha$ & $1023.00 \pm 252.10$ & $99.74 \pm 21.77^{\tau \tau}$ & $515.30 \pm 77.06$ & $362.80 \pm 47.70$ & $73.85 \pm 15.04$ & $346.10 \pm 41.46^{\star \star \star}$ & $286.90 \pm 44.40$ & $366.10 \pm 23.44$ \\
\hline CCL4/MIP-1 $\beta$ & $40.83 \pm 8.61$ & $8.71 \pm 1.24^{\tau \tau}$ & $21.83 \pm 4.15$ & $40.93 \pm 4.74^{\star \star}$ & $8.96 \pm 2.82$ & $36.65 \pm 4.08^{\star \star \star}$ & $18.59 \pm 1.98$ & $40.43 \pm 2.62^{\star \star \star}$ \\
\hline CCL2/MCP-1 & $542.50 \pm 117.10$ & $93.71 \pm 11.92^{\tau \tau}$ & $1244.00 \pm 213.40$ & $516.20 \pm 71.17^{\tau \tau}$ & $183.80 \pm 51.99$ & $585.40 \pm 61.80^{\star \star \star}$ & $827.00 \pm 188.20$ & $486.40 \pm 35.50$ \\
\hline CXCL1/KC & $533.10 \pm 57.85$ & $80.39 \pm 10.84^{\tau \tau \tau}$ & $496.70 \pm 65.65$ & $655.90 \pm 70.33$ & $297.00 \pm 67.81$ & $751.40 \pm 77.80^{\star \star \star}$ & $345.20 \pm 55.87$ & $625.50 \pm 31.55^{\star \star \star}$ \\
\hline CCL5/RANTES & $582.60 \pm 114.80$ & $305.40 \pm 71.84$ & $285.20 \pm 27.58$ & $1402.00 \pm 240.60^{\star \star \star}$ & $201.50 \pm 39.46$ & $1623.00 \pm 219.30^{\star \star \star}$ & $214.70 \pm 45.55$ & $1377.00 \pm 162.90^{\star \star \star \star}$ \\
\hline
\end{tabular}

Data shown are expressed as mean \pm SEM and are cumulative of three experiments using four mice per group per time point.

Bolded values indicate significance either increased or decreased compared to HKH99y.

${ }^{*} p<0.05,{ }^{* *} p<0.005,{ }^{* * *} p<0.0001$ significant increase compared to HKH99\%.

${ }^{\tau} p<0.05,{ }^{\pi p} p<0.005,{ }^{\pi \tau} p<0.0001$ significant decrease compared to HKH99\%. 
mice that were subsequently depleted of both $\mathrm{CD}^{+}$and $\mathrm{CD}^{+}$ $\mathrm{T}$ cells were shown to have an $80 \%$ survival rate following challenge with C. neoformans strain H99. Therefore, we sought to determine the necessity of $\mathrm{T}$ cells in protection against cryptococcosis caused by the different serotypes of Cryptococcus in H99 $\gamma$ immunized mice. For this, BALB/c mice were immunized with $C$. neoformans strain $\mathrm{H} 99 \gamma$ and allowed 70 days to resolve the infection. Mice were then depleted of $\mathrm{CD}^{+}$and/or $\mathrm{CD}^{+}$ $\mathrm{T}$ cells or received isotype control antibody two days prior to challenge and weekly thereafter during the observation period. $\mathrm{H} 99 \gamma$ immunized mice depleted of both $\mathrm{CD}^{+}$and $\mathrm{CD} 8^{+} \mathrm{T}$ cells prior to and during challenge with $\mathrm{H} 99$ demonstrated an $87.5 \%$ survival rate upon the conclusion of the study (Figure 4A) as previously demonstrated (40). Figure 4 shows that $\mathrm{H} 99 \gamma$ immunized mice treated with isotype control antibodies and challenged with R265 (Figure 4B) or R4247 (Figure 4D) had similar prolonged survival (median survival times of 65 and 64.5 days for R265 and R4247 challenged mice, respectively); similar to observations demonstrated in Figure 1B. In contrast, we observed $100 \%$ mortality in H99 $\gamma$ immunized mice depleted of $\mathrm{CD}^{+} \mathrm{T}$ cells alone during challenge with R265 (median survival of 35.5 days) or depleted of $\mathrm{CD}^{+}$and $\mathrm{CD} 8^{+} \mathrm{T}$ cells (median survival of 34 days; Figure 4B). Interestingly, H99 $\gamma$ immunized mice depleted of $\mathrm{CD}^{+} \mathrm{T}$ cells alone and challenged with R265 showed increased, although not statistically significant, survival (median survival of 80 days) compared to that observed in isotype control-treated mice (median survival of 65 days). We also observed that $\mathrm{H} 99 \gamma$ immunized mice challenged with R4247 while depleted of $\mathrm{CD} 4^{+} \mathrm{T}$ cells alone experienced $87.5 \%$ mortality (median survival time of 30.5 days) and $100 \%$ mortality upon depletion of both $\mathrm{CD}^{+}$and $\mathrm{CD} 8^{+} \mathrm{T}$ cells (median survival time of 31.5 days; Figure 4D). Additionally, H99 $\gamma$ immunized mice depleted of $\mathrm{CD}^{+} \mathrm{T}$ cells alone and challenged with R4247 had increased survival although not statistically significant (median survival of 75.5 days) compared to the isotype control-treated mice (median survival of 64.5 days). Mice immunized with $\mathrm{H} 99 \gamma$ and subsequently depleted of $\mathrm{CD}^{+} \mathrm{T}$ and/or $\mathrm{CD}^{+} \mathrm{T}$ cells prior to and during challenge with WSA87 did not show any difference in survival compared to the isotype control-treated mice (Figure 4C). Overall, we observed that depletion of $\mathrm{CD}^{+} \mathrm{T}$ cells resulted in a significant loss of protection against challenge with R265 (serotype B) or R4247 (serotype D) in H99 (serotype A) immunized mice, indicating that $\mathrm{CD} 4^{+} \mathrm{T}$ cells are required for broad-spectrum protection against these serotypes.

\section{DISCUSSION}

While the overwhelming majority of Cryptococcus exposures do not progress to life-threatening illness, the ubiquitous presence of Cryptococcus in the environment world-wide indicates that exposure to persons predicted to be at an exceptionally high risk for developing cryptococcosis (i.e., patients scheduled to receive organ transplants, otherwise healthy $\mathrm{HIV}^{+}$persons, and immune competent persons in areas observed to contain C. gattii) is inevitable and supports the need for development of a prophylactic and/or therapeutic vaccine that provides broad-spectrum protection against multiple Cryptococcus serotypes (9-16, 42). We have previously shown that mice immunized with $C$. neoformans strain $\mathrm{H} 99 \gamma$, serotype A, are protected against a subsequent otherwise lethal challenge with wild-type C. neoformans strain H99 (25, 36-38, 40, 41, 43-45). Herein, we demonstrate the potential for achieving broad-spectrum protection against multiple clinically relevant strains of Cryptococcus serotypes following vaccination with a Cryptococcus serotype A strain previously shown to elicit protective immunity against C. neoformans. Specifically, we demonstrated that mice immunized with Cryptococcus strain $\mathrm{H} 99 \gamma$, serotype A, develop significant protection against challenge with serotypes A, B, or D of Cryptococcus. Our data are in line with a similar study showing that mice vaccinated with an avirulent chitosan-deficient $C$. neoformans strain also created from a serotype A background strain exhibited significantly delayed mortality when challenged with serotype B C. gattii strains R265 or WM276 (34). Altogether, these studies clearly demonstrate that significant cross-protection can be developed following vaccination with a Cryptococcus strain of a disparate serotype and provide further proof-of-principle for the development of a prophylactic vaccine that can protect against multiple disparate Cryptococcus serotypes.

Both clinical and experimental studies have shown that Th1-type $\mathrm{CD}^{+} \mathrm{T}$ CMI is critical for protection against cryptococcosis $(24,25,46)$. We observed a predominantly Th1-type and proinflammatory cytokine profile and increased survival in $\mathrm{H} 99 \gamma$ immunized mice following challenge with representative Cryptococcus serotypes B or D. Additionally, intracellular cytokine staining of $\mathrm{CD}^{+} \mathrm{T}$ cells showed that H99 $\gamma$ immunized mice were capable of eliciting a predominantly Th1-type anamnestic immune response upon subsequent challenge with the other Cryptococcus serotypes. These studies indicated that a Th1-type cell-mediated immune response was responsible for the increased survival observed in H99 immunized mice challenged with Cryptococcus strains from serotypes B or D. We also observed increases in some Th2-type cytokines in H99 $\gamma$ immunized mice; however, the overall low levels observed are unlikely to be biologically relevant and were not as significant as the levels observed in HKH99 $\gamma$ immunized mice at day 14 post challenge. These findings do suggest that a Th1-Th2 balance may be important to achieve an optimal host immune response against Cryptococcus (47). Additionally, we observed an overall increase in the total number of infiltrating leukocytes in $\mathrm{H} 99 \gamma$ immunized mice compared to HKH99 $\gamma$ immunized mice challenged with their equivalent serotypes. Dendritic cells are known to play a vital role in the initial response against $C$. neoformans with the ability to phagocytose and kill the fungal organisms (48, 49). The significant increase in the infiltration of CD $11 \mathrm{~b}^{+} / \mathrm{CD} 11 \mathrm{c}^{+}$ cells in mice given the H99 $\gamma$ immunization prior to challenge with the different serotypes compared to HKH99 $\gamma$ immunized mice correlates with reduced fungal burden in these mice. We did observe an increase in $\mathrm{F} 4 / 80^{+}$cells in H99 $\gamma$ immunized mice. However, previous studies in our laboratory has demonstrated that quantity of macrophages does not correlate with clearance, rather the ability of $\mathrm{F} 4 / 80^{+}$cells to polarize to a classically activated, M1 phenotype promotes clearance of $C$. neoformans $(36,41,43,50)$. The increase in infiltrating $\mathrm{Ly}_{6 \mathrm{G}} \mathrm{G}^{+}$cells correlates with significant increases in known neutrophil chemoattractants 


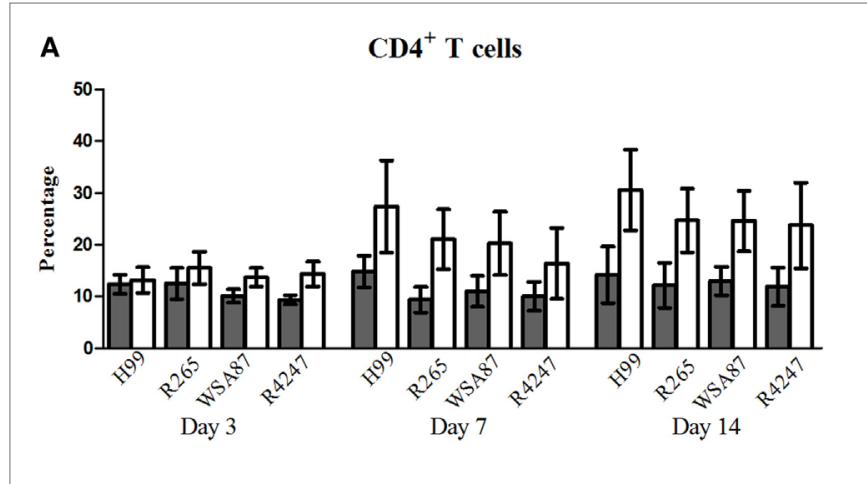

-

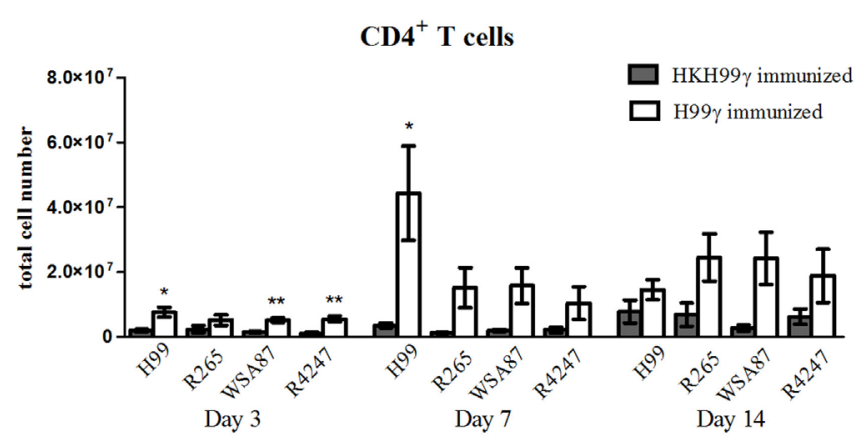

B $\quad \mathrm{CD8}^{+} \mathrm{T}$ cells
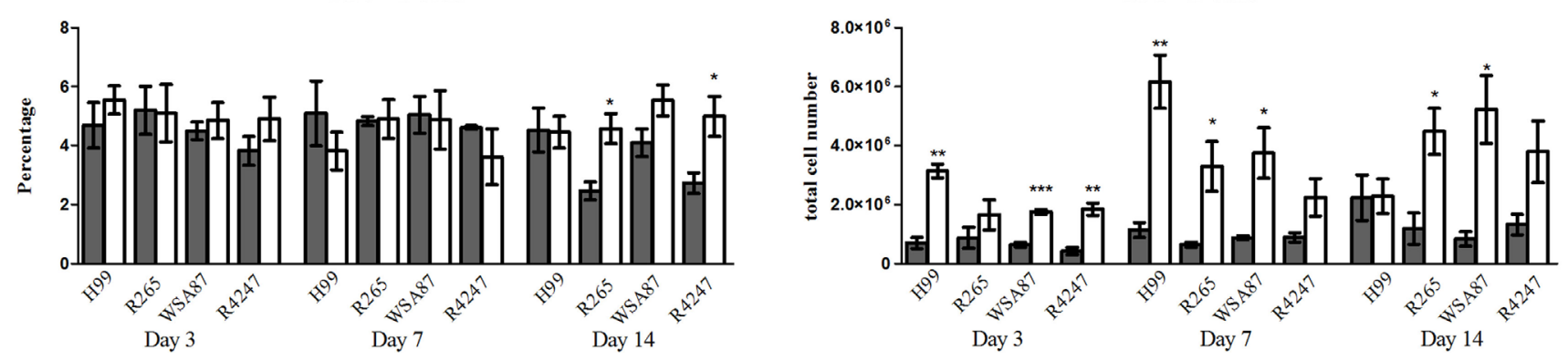

C

$\mathrm{CD4}^{+}$IFN- $\boldsymbol{\gamma}^{+}$T cells

D
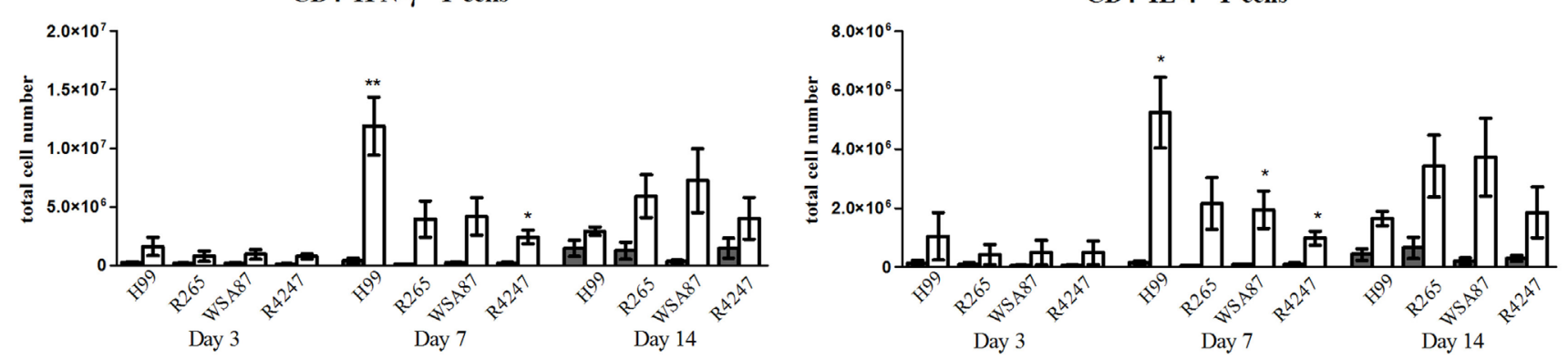

E

$\mathrm{CD}^{+}{ }^{+} \mathrm{IL}-17^{+}$T Cells

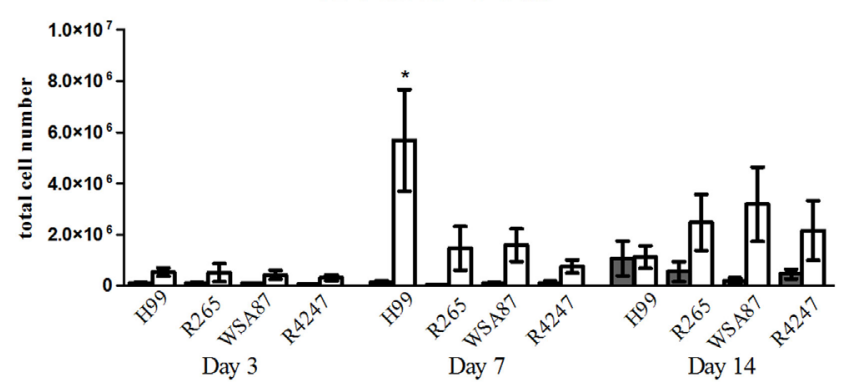

FIGURE 3 | Pulmonary T cell recruitment in immunized mice challenged with disparate serotypes of Cryptococcus. BALB/c mice were immunized intranasally with

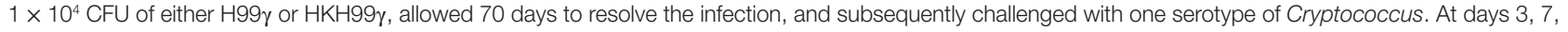
and 14 post challenge, lungs were excised, tissues digested, and pulmonary immune cell infiltrates were analyzed by flow cytometry (A,B) as described previously in Figure $\mathbf{2}$ or further permeabilized to stain for intracellular cytokines (C-E). Data shown are the mean \pm SEM of absolute cell numbers or percentage from three independent experiments performed using 4 mice per group per experiment. ${ }^{\star} p<0.05,{ }^{\star *} p<0.005,{ }^{\star \star *} p<0.0001$. ${ }^{\star}$ Significant increase compared to HKH99 $\gamma$. 

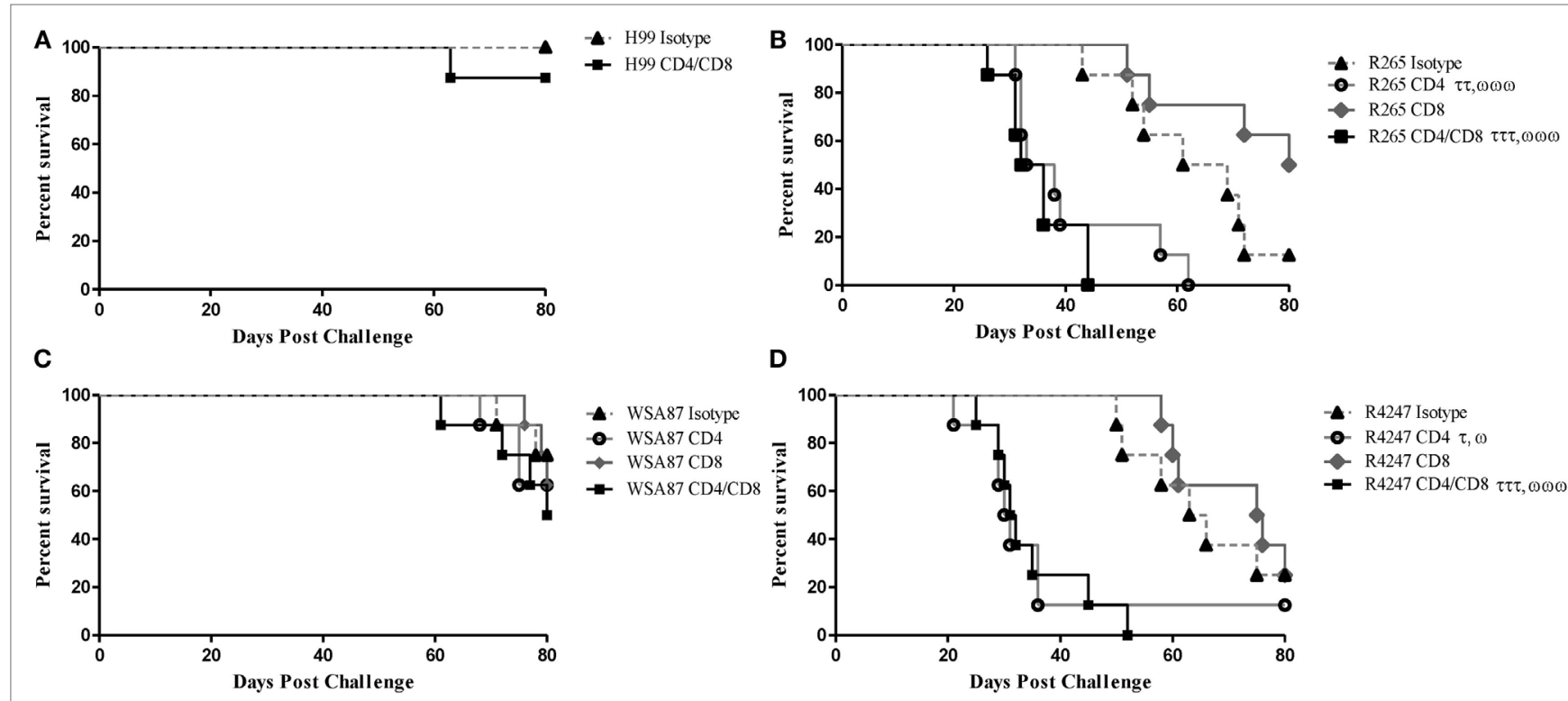

D

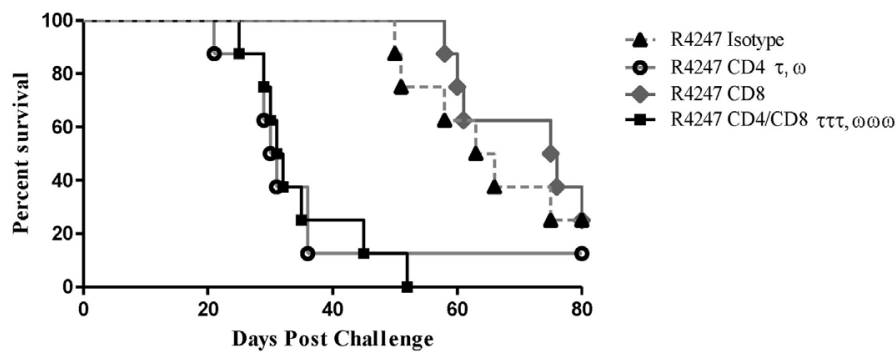

FIGURE 4 | Protection mediated by immunization with C. neoformans strain H99 $\gamma$, serotype A, appears to be predominantly CD4+ ${ }^{+}$cell-mediated. BALB/c mice were immunized intranasally with $1 \times 10^{4} \mathrm{CFU}$ of H99y and allowed 70 days to rest. Mice were depleted of $\mathrm{CD} 4^{+} \mathrm{T}$ cells, $\mathrm{CD} 8^{+} \mathrm{T}$ cells, or both $\mathrm{CD} 4^{+} / \mathrm{CD} 8^{+} \mathrm{T}$ cell subsets or received isotype control antibody two days prior to challenge with one serotype of Cryptococcus and weekly thereafter during the observation period. Mice were observed for up to $80 \mathrm{~d}$ post challenge for survival analysis. Survival data shown are from one experiment each, using 8 mice per group. However, the results are shown for individual groups and mice challenged with H99 (A), R265 (B), WSA87 (C) or R4247 (D) for simplicity. ${ }^{\tau} p<0.05,{ }^{\tau \tau} p<0.005,{ }^{\tau \tau \tau} p<0.0001$. $\tau=$ significant decrease compared to isotype; ${ }^{\omega} p<0.05$, ${ }^{\omega} p<0.005$, ${ }^{\omega \omega} p<0.0001 . \omega=$ significant decrease compared to CD8 ${ }^{+}$T cell depleted.

[IL-17A, G-CSF (indirect chemotaxis), and CXCL1/KC] in the H99 $\gamma$ immunized mice $(51,52)$. However, previous studies from our lab demonstrate that neutrophils are not critical for clearance of C. neoformans strain H99 in H99y immunized mice (44).

The vast majority of patients who acquire cryptococcosis due to $C$. neoformans are severely immunocompromized while those who acquire C. gattii infections appear to have little to no known immunodeficiency (53-55). Nonetheless, the protection observed in $\mathrm{H} 99 \gamma$ immunized mice challenged with serotypes B or $\mathrm{D}$ appeared to be $\mathrm{CD}^{+} \mathrm{T}$ cell-dependent. Interestingly, depletion of $\mathrm{CD}^{+} \mathrm{T}$ cells appeared to partially enhance survival in $\mathrm{H} 99 \gamma$ immunized mice challenged with serotypes B or D. We hypothesize that this additional protection may be attributed to a reduction in putative deleterious $\mathrm{CD}^{+} \mathrm{T}$ cell-mediated inflammatory responses or regulatory function in $\mathrm{CD}^{+} \mathrm{T}$ cell depleted mice challenged with serotypes $\mathrm{B}$ or D; however, this hypothesis will need to be confirmed in follow-up studies. In contrast, significant protection was evident in $\mathrm{H} 99 \gamma$ immunized mice rendered $\mathrm{CD} 4^{+}$ and $\mathrm{CD}^{+} \mathrm{T}$ cell deficient and challenged with the serotype A Cryptococcus strain, H99. These studies demonstrate that immunization with $\mathrm{H} 99 \gamma$ produces memory $\mathrm{T}$ cells that allow for a rapid response against the invading cryptococcal strain as previously shown in our studies (40). Subtle species-specific differences in an antigen's peptide sequence and/or structure in the different serotypes tested may account for the lack of complete protection observed in our studies. Without the memory T cells present, there is no delay in onset of disease and the $\mathrm{CD} 4^{+} \mathrm{T}$ cell deficient mice challenged with serotypes $\mathrm{B}$ or $\mathrm{D}$ succumb to infection at a rate similar to the mice that were immunized with HKH99 $\gamma$. Recent studies have shown increased protection against C. neoformans and C. gattii using a vaccine formulation comprised of antigens extracted from capsule or chitosan deficient Cryptococcus strains by treatment with an alkaline solution and packaged into GPs (33). The source of antigens for each vaccine formulation was specifically tailored to each challenge (i.e., C. neoformans antigens for C. neoformans challenge), and thus, the efficacy for the formulations to provide cross-protection was not determined. However, these studies also suggested that the protection induced following immunization with the Cryptococcus antigen/GP formulation against $C$. neoformans challenge was dependent on T CMI (33). The protection observed in T cell-deficient, H99 $\gamma$ immunized mice against a subsequent serotype A challenge may be antibody-mediated or may be suggestive of a trained innate cell population that compensates for the lack of T cells. Although we did observe an increase in the total number of B cells in $\mathrm{H} 99 \gamma$ immunized mice compared to HKH99 $\gamma$ immunized mice on days 7 and 14 post challenge, previous studies from our lab show that $\mathrm{B}$ cells are not required for the generation of protective immunity against cryptococcosis in $\mathrm{H} 99 \gamma$ immunized mice suggesting that antibody-mediated protection in the absence of T cells is unlikely (25). Overall, immunization with H99 $\gamma$ resulted in a non-T cell dependent protective immune response to challenge with a serotype A Cryptococcus strain showing that long-term protection in immunocompromized hosts can be generated. However, our results showing that $\mathrm{CD} 4^{+} \mathrm{T}$ cells are required for the protection observed in $\mathrm{H} 99 \gamma$ immunized mice challenged with serotypes $\mathrm{B}$ and $\mathrm{D}$ suggests that a vaccine formulation designed to induce complete protection against multiple Cryptococcus serotypes 
should include antigens specific to each serotype or contain antigens with significant homology across the serotypes.

Our studies also showed that the serotype C Cryptococcus strain used herein, WSA87, is less virulent or remains latent in mice compared to all the other strains tested. When H99 $\gamma$ immunized mice were subsequently challenged with WSA87, we observed a statistically significant increase in immune cell infiltrates at day 7 post challenge compared to HKH99 $\gamma$ immunized mice which correlated with the significant decrease of fungal burden in $\mathrm{H} 99 \gamma$ immunized mice. However, survival during challenge with serotype $\mathrm{C}$ was similar regardless of the immunization strategy most likely due to the initial low virulence of this strain or the strain's ability to remain latent with mice not succumbing to infection until almost day 90 post challenge. Also, depletion of $\mathrm{CD}^{+}$and/ or $\mathrm{CD}^{+} \mathrm{T}$ cells was observed to have no impact on the survival of H99 $\gamma$ immunized mice challenged with WSA87. The results suggest that WSA87 suppresses T CMI or that protection against WSA87 is not dependent on T CMI. The serotype C strain chosen for this study was a clinical isolate that caused human disease; however, virulence due to this strain appeared to be relatively low in mice. Cryptococcus strains of the same serotype are known to exhibit significant variability in virulence within murine models. Thus, it is inappropriate to suggest that the serotypes utilized in our study are completely representative of all Cryptococcus strains within their serotype. However, these specific results suggest an unfortunate and perhaps unavoidable reality that developing vaccine formulations that target the more pathogenic Cryptococcus strains may still allow for less virulent strains of Cryptococcus to slip under the host's immunological radar resulting in disease and mortality.

While no fungal vaccines are clinically available, an ideal vaccine would mirror the results of the currently available vaccines against other microbial pathogens that can protect against multiple serotypes. The quadrivalent meningococcal conjugate vaccine (MenACWY-D; Menactra ${ }^{\circledR}$, Sanofi Pasteur, Swiftwater, PA, USA), for example, contains polysaccharides from serotypes A, C, Y, and W-135 meningococci conjugated to a diphtheria protein carrier (56) and provides broad-spectrum protection against those serotypes that cause the majority of meningococcal disease. While the studies presented herein determined the efficacy of vaccination with one serotype to provide crossprotection against other serotypes, our results suggest that the identification and inclusion of multiple cross-protective CD4 ${ }^{+}$ $\mathrm{T}$ cell-dependent antigens will be critical for the development

\section{REFERENCES}

1. Hagen F, Khayhan K, Theelen B, Kolecka A, Polacheck I, Sionov E, et al. Recognition of seven species in the Cryptococcus gattii/Cryptococcus neoformans species complex. Fungal Genet Biol (2015) 78:16-48. doi:10.1016/j. fgb.2015.02.009

2. Vibhagool A, Sungkanuparph S, Mootsikapun P, Chetchotisakd P, Tansuphaswaswadikul S, Bowonwatanuwong C, et al. Discontinuation of secondary prophylaxis for cryptococcal meningitis in human immunodeficiency virus-infected patients treated with highly active antiretroviral therapy: a prospective, multicenter, randomized study. Clin Infect Dis (2003) 36(10):1329-31. doi:10.1086/374849

3. Rajasingham R, Smith RM, Park BJ, Jarvis JN, Govender NP, Chiller TM, et al. Global burden of disease of HIV-associated cryptococcal meningitis: an of a vaccine formulation that elicits broad-spectrum protection against Cryptococcus strains that cause the majority of clinical disease. Although much work remains toward the development of a cross-protective cryptococcal vaccine, these studies provide a foundation for understanding the protective host immune response to multiple clinically relevant strains of Cryptococcus and the need to identify protective $\mathrm{CD} 4^{+} \mathrm{T}$ cell epitopes that can be incorporated into a vaccine formulation that provides broadspectrum protection against cryptococcosis.

\section{ETHICS STATEMENT}

This study was carried out in accordance with the recommendations of the Institutional Animal Care and Use Committee (protocol number MU021) of the University of Texas at San Antonio.

\section{AUTHOR CONTRIBUTIONS}

FW designed study, performed statistical analysis, interpreted study results, and participated in drafting and editing of manuscript. MD assisted in study design, performed experiments and statistical analysis, participated in interpretation of results, and drafted manuscript. AC, SH, CW, NC-L, CH, and KW performed experiments and statistical analysis, participated in interpretation of results and manuscript revision.

\section{ACKNOWLEDGMENTS}

The funders had no role in study design, data collection and analysis, decision to publish, or preparation of the manuscript.

\section{FUNDING}

Supported by research grants 2RO1AI071752 (FW) and 2RO1AI071752-08S1 (MD) from the National Institute of Allergy and Infectious Diseases (NIAID) of the National Institutes of Health (NIH) and grant GM060655 (MD) from the National Institute of General Medical Sciences of the NIH.

\section{SUPPLEMENTARY MATERIAL}

The Supplementary Material for this article can be found online at http://www.frontiersin.org/article/10.3389/fimmu.2017.01359/ full\#supplementary-material.

updated analysis. Lancet Infect Dis (2017) 17(8):873-81. doi:10.1016/S14733099(17)30243-8

4. Maziarz EK, Perfect JR. Cryptococcosis. Infect Dis Clin North Am (2016) 30(1):179-206. doi:10.1016/j.idc.2015.10.006

5. Perez C, Dolande M, Moya M, Rosello A, de Capriles CR, Landaeta ME, et al. Cryptococcus neoformans, Cryptococcus gattii: serotypes in Venezuela. Mycopathologia (2008) 166(3):149-53. doi:10.1007/s11046-008-9132-1

6. Kwon-Chung KJ, Bennett JE. Epidemiologic differences between the two varieties of Cryptococcus neoformans. Am J Epidemiol (1984) 120(1):123-30. doi:10.1093/oxfordjournals.aje.a113861

7. Lizarazo J, Escandon P, Agudelo CI, Firacative C, Meyer W, Castaneda E Retrospective study of the epidemiology and clinical manifestations of Cryptococcus gattii infections in Colombia from 1997-2011. PLoS Negl Trop Dis (2014) 8(11):e3272. doi:10.1371/journal.pntd.0003272 
8. MacDougall L, Fyfe M, Romney M, Starr M, Galanis E. Risk factors for Cryptococcus gattii infection, British Columbia, Canada. Emerg Infect Dis (2011) 17(2):193-9. doi:10.3201/eid1702.101020

9. Byrnes EJ, Heitman J.Cryptococcus gattii outbreak expands into the Northwestern United States with fatal consequences. F1000 Biol Rep (2009) 1:62. doi:10.3410/B1-62

10. Byrnes EJ III, Li W, Lewit Y, Perfect JR, Carter DA, Cox GM, et al. First reported case of Cryptococcus gattii in the Southeastern USA: implications for travel-associated acquisition of an emerging pathogen. PLoS One (2009) 4(6):e5851. doi:10.1371/journal.pone.0005851

11. Datta K, Bartlett KH, Baer R, Byrnes E, Galanis E, Heitman J, et al. Spread of Cryptococcus gattii into pacific northwest region of the United States. Emerg Infect Dis (2009) 15(8):1185-91. doi:10.3201/eid1508.081384

12. Datta K, Bartlett KH, Marr KA. Cryptococcus gattii: emergence in Western North America: exploitation of a novel ecological niche. Interdiscip Perspect Infect Dis (2009) 2009:176532. doi:10.1155/2009/176532

13. Galanis E, Macdougall L, Kidd S, Morshed M; British Columbia Cryptococcus gattii Working Group. Epidemiology of Cryptococcus gattii, British Columbia, Canada, 1999-2007. Emerg Infect Dis (2010) 16(2):251-7. doi:10.3201/ eid1602.090900

14. Hagen F, Colom MF, Swinne D, Tintelnot K, Iatta R, Montagna MT, et al. Autochthonous and dormant Cryptococcus gattii infections in Europe. Emerg Infect Dis (2012) 18(10):1618-24. doi:10.3201/eid1810.120068

15. McCulloh RJ, Phillips R, Perfect JR, Byrnes EJ III, Heitman J, Dufort E. Cryptococcus gattii genotype VGI infection in New England. Pediatr Infect Dis $J$ (2011) 30(12):1111-4. doi:10.1097/INF.0b013e31822d14fd

16. Walraven CJ, Gerstein W, Hardison SE, Wormley F, Lockhart SR, Harris JR, et al. Fatal disseminated Cryptococcus gattii infection in New Mexico. PLoS One (2011) 6(12):e28625. doi:10.1371/journal.pone.0028625

17. Kwon-Chung KJ, Fraser JA, Doering TL, Wang Z, Janbon G, Idnurm A, et al. Cryptococcus neoformans and Cryptococcus gattii, the etiologic agents of cryptococcosis. Cold Spring Harb Perspect Med (2014) 4(7):a019760. doi:10.1101/ cshperspect.a019760

18. Chen SC, Slavin MA, Heath CH, Playford EG, Byth K, Marriott D, et al. Clinical manifestations of Cryptococcus gattii infection: determinants of neurological sequelae and death. Clin Infect Dis (2012) 55(6):789-98. doi:10.1093/ $\mathrm{cid} / \mathrm{cis} 529$

19. Ngamskulrungroj P, Chang Y, Sionov E, Kwon-Chung KJ. The primary target organ of Cryptococcus gattii is different from that of Cryptococcus neoformans in a murine model. mBio (2012) 3(3):e00103-12. doi:10.1128/mBio. 00103-12

20. Speed B, Dunt D. Clinical and host differences between infections with the two varieties of Cryptococcus neoformans. Clin Infect Dis (1995) 21(1):28-34; discussion 5-6. doi:10.1093/clinids/21.1.28

21. Lomes NR, Melhem MS, Szeszs MW, Martins Mdos A, Buccheri R. Cryptococcosis in non-HIV/non-transplant patients: a Brazilian case series. Med Mycol (2016) 54(7):669-76. doi:10.1093/mmy/myw021

22. Mitchell DH, Sorrell TC, Allworth AM, Heath CH, McGregor AR, Papanaoum $\mathrm{K}$, et al. Cryptococcal disease of the CNS in immunocompetent hosts: influence of cryptococcal variety on clinical manifestations and outcome. Clin Infect Dis (1995) 20(3):611-6. doi:10.1093/clinids/20.3.611

23. Perfect JR, Cox GM. Drug resistance in Cryptococcus neoformans. Drug Resist Updat (1999) 2(4):259-69. doi:10.1054/drup.1999.0090

24. Olszewski MA, Zhang Y, Huffnagle GB. Mechanisms of cryptococcal virulence and persistence. Future Microbiol (2010) 5(8):1269-88. doi:10.2217/ fmb. 10.93

25. Wozniak KL, Ravi S, Macias S, Young ML, Olszewski MA, Steele C, et al. Insights into the mechanisms of protective immunity against Cryptococcus neoformans infection using a mouse model of pulmonary cryptococcosis. PLoS One (2009) 4(9):e6854. doi:10.1371/journal.pone.0006854

26. Angkasekwinai P, Sringkarin N, Supasorn O, Fungkrajai M, Wang YH, Chayakulkeeree M, et al. Cryptococcus gattii infection dampens Th1 and Th17 responses by attenuating dendritic cell function and pulmonary chemokine expression in the immunocompetent hosts. Infect Immun (2014) 82(9):3880-90. doi:10.1128/IAI.01773-14

27. Cheng PY, Sham A, Kronstad JW. Cryptococcus gattii isolates from the British Columbia cryptococcosis outbreak induce less protective inflammation in a murine model of infection than Cryptococcus neoformans. Infect Immun (2009) 77(10):4284-94. doi:10.1128/IAI.00628-09
28. Dong ZM, Murphy JW. Effects of the two varieties of Cryptococcus neoformans cells and culture filtrate antigens on neutrophil locomotion. Infect Immun (1995) 63(7):2632-44.

29. Huston SM, Li SS, Stack D, Timm-McCann M, Jones GJ, Islam A, et al. Cryptococcus gattii is killed by dendritic cells, but evades adaptive immunity by failing to induce dendritic cell maturation. J Immunol (2013) 191(1):249-61. doi:10.4049/jimmunol.1202707

30. Wright L, Bubb W, Davidson J, Santangelo R, Krockenberger M, Himmelreich $\mathrm{U}$, et al. Metabolites released by Cryptococcus neoformans var. neoformans and var. gattii differentially affect human neutrophil function. Microbes Infect (2002) 4(14):1427-38. doi:10.1016/S1286-4579(02)00024-2

31. Urai M, Kaneko Y, Ueno K, Okubo Y, Aizawa T, Fukazawa H, et al. Evasion of innate immune responses by the highly virulent Cryptococcus gattii by altering capsule glucuronoxylomannan structure. Front Cell Infect Microbiol (2015) 5:101. doi:10.3389/fcimb.2015.00101

32. Hole CR, Wormley FL Jr. Vaccine and immunotherapeutic approaches for the prevention of cryptococcosis: lessons learned from animal models. Frontiers Microbiol (2012) 3:291. doi:10.3389/fmicb.2012.00291

33. Specht CA, Lee CK, Huang H, Tipper DJ, Shen ZT, Lodge JK, et al. Protection against experimental cryptococcosis following vaccination with glucan particles containing Cryptococcus alkaline extracts. mBio (2015) 6(6):e1905-15. doi:10.1128/mBio.01905-15

34. Upadhya R, Lam WC, Maybruck B, Specht CA, Levitz SM, Lodge JK. Induction of protective immunity to cryptococcal infection in mice by a heat-killed, chitosan-deficient strain of Cryptococcus neoformans. mBio (2016) 7(3):e00547-16. doi:10.1128/mBio.00547-16

35. Rella A, Mor V, Farnoud AM, Singh A, Shamseddine AA, Ivanova E, et al. Role of sterylglucosidase 1 (Sgl1) on the pathogenicity of Cryptococcus neoformans: potential applications for vaccine development. Frontiers Microbiol (2015) 6:836. doi:10.3389/fmicb.2015.00836

36. Hardison SE, Herrera G, Young ML, Hole CR, Wozniak KL, Wormley FL Jr. Protective immunity against pulmonary cryptococcosis is associated with STAT1-mediated classical macrophage activation. JImmunol (2012) 189(8):4060-8. doi:10.4049/jimmunol.1103455

37. Hardison SE, Ravi S, Wozniak KL, Young ML, Olszewski MA, Wormley FL Jr. Pulmonary infection with an interferon-gamma-producing Cryptococcus neoformans strain results in classical macrophage activation and protection. Am J Pathol (2010) 176(2):774-85. doi:10.2353/ajpath.2010.090634

38. Wormley FL Jr, Perfect JR, Steele C, Cox GM. Protection against cryptococcosis by using a murine gamma interferon-producing Cryptococcus neoformans strain. Infect Immun (2007) 75(3):1453-62. doi:10.1128/IAI.00274-06

39. Wozniak KL, Hardison S, Olszewski M, Wormley FL Jr. Induction of protective immunity against cryptococcosis. Mycopathologia (2012) 173(5-6):387-94. doi:10.1007/s11046-011-9505-8

40. Wozniak KL, Young ML, Wormley FL Jr. Protective immunity against experimental pulmonary cryptococcosis in T cell-depleted mice. Clin Vaccine Immunol (2011) 18(5):717-23. doi:10.1128/CVI.00036-11

41. Leopold Wager CM, Hole CR, Wozniak KL, Olszewski MA, Mueller M, Wormley FL Jr. STAT1 signaling within macrophages is required for antifungal activity against Cryptococcus neoformans. Infect Immun (2015) 83(12):4513-27. doi:10.1128/IAI.00935-15

42. Park BJ, Wannemuehler KA, Marston BJ, Govender N, Pappas PG, Chiller TM. Estimation of the current global burden of cryptococcal meningitis among persons living with HIV/AIDS. AIDS (2009) 23(4):525-30. doi:10.1097/ QAD.0b013e328322ffac

43. Leopold Wager CM, Hole CR, Wozniak KL, Olszewski MA, Wormley FL Jr. STAT1 signaling is essential for protection against Cryptococcus neoformans infection in mice. J Immunol (2014) 193(8):4060-71. doi:10.4049/ jimmunol.1400318

44. Wozniak KL, Kolls JK, Wormley FL Jr. Depletion of neutrophils in a protective model of pulmonary cryptococcosis results in increased IL-17A production by gammadelta T cells. BMC Immunol (2012) 13:65. doi:10.1186/14712172-13-65

45. Wozniak KL, Hardison SE, Kolls JK, Wormley FL. Role of IL-17A on resolution of pulmonary C. neoformans infection. PLoS One (2011) 6(2):e17204. doi:10.1371/journal.pone.0017204

46. Chaturvedi AK, Wormley FL Jr. Cryptococcus antigens and immune responses: implications for a vaccine. Expert Rev Vaccines (2013) 12(11):1261-72. doi:10. 1586/14760584.2013.840094 
47. Koguchi Y, Kawakami K. Cryptococcal infection and Th1-Th2 cytokine balance. Int Rev Immunol (2002) 21(4-5):423-38. doi:10.1080/08830180213274

48. Osterholzer JJ, Milam JE, Chen GH, Toews GB, Huffnagle GB, Olszewski MA. Role of dendritic cells and alveolar macrophages in regulating early host defense against pulmonary infection with Cryptococcus neoformans. Infect Immun (2009) 77(9):3749-58. doi:10.1128/IAI.00454-09

49. Wozniak KL, Levitz SM. Cryptococcus neoformans enters the endolysosomal pathway of dendritic cells and is killed by lysosomal components. Infect Immun (2008) 76(10):4764-71. doi:10.1128/IAI.00660-08

50. Arora S, Olszewski MA, Tsang TM, McDonald RA, Toews GB, Huffnagle GB. Effect of cytokine interplay on macrophage polarization during chronic pulmonary infection with Cryptococcus neoformans. Infect Immun (2011) 79(5):1915-26. doi:10.1128/IAI.01270-10

51. Mellett M, Atzei P, Horgan A, Hams E, Floss T, Wurst W, et al. Orphan receptor IL-17RD tunes IL-17A signalling and is required for neutrophilia. Nat Commun (2012) 3:1119. doi:10.1038/ncomms2127

52. Yong KL. Granulocyte colony-stimulating factor (G-CSF) increases neutrophil migration across vascular endothelium independent of an effect on adhesion: comparison with granulocyte-macrophage colony-stimulating factor (GM-CSF). Br J Haematol (1996) 94(1):40-7. doi:10.1046/j.1365-2141.1996. d01-1752.x

53. Chen SC-A, Meyer W, Sorrell TC. Cryptococcus gattii infections. Clin Microbiol $\operatorname{Rev}(2014)$ 27(4):980-1024. doi:10.1128/cmr.00126-13
54. Rosen LB, Freeman AF, Yang LM, Jutivorakool K, Olivier KN, Angkasekwinai $\mathrm{N}$, et al. Anti-GM-CSF autoantibodies in patients with cryptococcal meningitis. J Immunol (2013) 190(8):3959-66. doi:10.4049/jimmunol.1202526

55. Saijo T, Chen J, Chen SC, Rosen LB, Yi J, Sorrell TC, et al. Anti-granulocytemacrophage colony-stimulating factor autoantibodies are a risk factor for central nervous system infection by Cryptococcus gattii in otherwise immunocompetent patients. mBio (2014) 5(2):e912-4. doi:10.1128/mBio. 00912-14

56. Pace D, Pollard AJ, Messonier NE. Quadrivalent meningococcal conjugate vaccines. Vaccine (2009) 27(Suppl 2):B30-41. doi:10.1016/j.vaccine.2009. 05.003

Conflict of Interest Statement: The authors declare that the research was conducted in the absence of any commercial or financial relationships that could be construed as a potential conflict of interest.

Copyright (c) 2017 Van Dyke, Chaturvedi, Hardison, Leopold Wager, Castro-Lopez, Hole, Wozniak and Wormley. This is an open-access article distributed under the terms of the Creative Commons Attribution License (CC BY). The use, distribution or reproduction in other forums is permitted, provided the original author(s) or licensor are credited and that the original publication in this journal is cited, in accordance with accepted academic practice. No use, distribution or reproduction is permitted which does not comply with these terms. 